\title{
Carnosic acid protects mice from high-fat diet-induced NAFLD by regulating MARCKS
}

\author{
HONG-MAO SONG ${ }^{1}$, XIANG LI ${ }^{2}$, YUAN-YUAN LIU ${ }^{3}$, WEI-PING LU ${ }^{3}$, ZHAO-HUI CUI ${ }^{3}$, \\ $\mathrm{LI} \mathrm{ZHOU}^{3}$, DI YAO ${ }^{3}$ and HONG-MAN ZHANG ${ }^{3}$ \\ Departments of ${ }^{1}$ Otolaryngology-Head and Neck Surgery and ${ }^{2}$ Clinical Laboratory, \\ Huai'an Hospital Affiliated to Xuzhou Medical University; ${ }^{3}$ Department of Endocrinology, \\ Huai'an First People's Hospital, Nanjing Medical University, Huai'an, Jiangsu 223300, P.R. China
}

Received July 28, 2016; Accepted January 24, 2018

DOI: $10.3892 /$ ijmm.2018.3593

\begin{abstract}
Non-alcoholic fatty liver disease (NAFLD) comprises a spectrum of liver damage characterized by abnormal hepatic fat accumulation and inflammatory response. Although the molecular mechanisms responsible for the disease are not yet fully understood, the pathogenesis of NAFLD likely involves multiple signals. The identification of effective therapeutic strategies to target these signals is of utmost importance. Carnosic acid (CA), as a phenolic diterpene with anticancer, anti-bacterial, anti-diabetic and neuroprotective properties, is produced by many species of the Lamiaceae family. Myristoylated alanine-rich C-kinase substrate (MARCKS) is a major protein kinase $\mathrm{C}$ (PKC) substrate in many different cell types. In the present study, wild-type C57BL/6 and MARCKSdeficient mice were randomly divided into the normal chow- or high-fat (HF) diet-fed groups. The HF diet increased the fasting glucose and insulin levels, and promoted glucose intolerance in the wild-type mice. MARCKS deficiency further upregulated intolerance, fasting glucose and insulin. The HF diet also promoted hepatic steatosis, serum alanine transaminase (ALT) and aspartate transaminase (AST) activity, inflammation and lipid accumulation in the wild-type mice. These responses were accelerated in the MARCKS-deficient mice. Importantly, increased inflammation and lipid accumulation were associated with phosphoinositide 3-kinase (PI3K)/AKT, NLR family pyrin domain containing 3 (NLRP3)/nuclear factor- $\kappa \mathrm{B}(\mathrm{NF}-\kappa \mathrm{B})$ and sterol regulatory element binding protein-1c (SREBP-1c) signaling pathway activation. The mice treated with CA exhibited a significantly improved glucose and insulin tolerance. The production of pro-inflammatory cytokines and lipid accumulation were suppressed by CA. Significantly, MARCKS
\end{abstract}

Correspondence to: Dr Hong-Man Zhang, Department of Endocrinology, Huai'an First People's Hospital, Nanjing Medical University, 6 Beijing Road West, Huai'an, Jiangsu 223300, P.R. China

E-mail: zhonghongmanhuaian@126.com

Key words: non-alcoholic fatty liver disease, carnosic acid, myristoylated alanine-rich C-kinase substrate, inflammation, lipid accumulation was reduced in mice fed the HF diet. CA treatment upregulated MARCKS expression compared to the HF group. Furthermore, the activation of the PI3K/AKT, NLRP3/NF- $\kappa$ B and SREBP-1c signaling pathways was inhibited by $\mathrm{CA}$. Taken together, our data suggest that CA suppresses inflammation and lipogenesis in mice fed a HF diet through MARCKS regulation. Thus, CA may be prove to be a useful anti-NAFLD agent.

\section{Introduction}

Non-alcoholic fatty liver disease (NAFLD) is rapidly becoming a serious global health concern due to its prevalence, which has rapidly increased with the prevalence of obesity and type 2 diabetes (T2D) (1,2). NAFLD comprises a spectrum of liver conditions. The dominant feature of NAFLD is the abundant accumulation of hepatic triglycerides (TGs). Non-alcoholic steatohepatitis (NASH), involving the presence of both lobular inflammation and signs of hepatocellular damage, can develop in the context of chronic NAFL $(3,4)$. Although the details mechanisms responsible for the disease remain to be fully understood, NASH is considered a liver-related complication, such as fibrosis, cirrhosis as well as hepatocellular carcinoma (5). Importantly, to date, there are no approved pharmacological therapeutic strategies for NAFLD, and it is presently the second-leading etiology for liver transplantation (6).

Carnosic acid (CA), known as a natural benzenediol abietane diterpene detected in rosemary and common sage. CA is used as a preservative or antioxidant in food and non-food products, including toothpaste, mouthwash and chewing gum $(7,8)$. CA has been reported to have antitumor properties in various types of cancer, such as adenoma formation, myeloid leukemia and skin tumors by regulating cancer cell growth, apoptosis and oxidative stress $(9,10)$.

Myristoylated alanine-rich protein kinase $\mathrm{C}$ substrate (MARCKS) is known as a major protein kinase $\mathrm{C}$ (PKC) substrate in different cell types (11). MARCKS is bound to the plasma membrane, and recent studies have indicated that this binding needs both hydrophobic insertion of its myristate chain to the bilayer and electrostatic interaction of its cluster of basic residues with acidic lipids $(12,13)$. The phosphorylation of MARCKS by PKC leads to negative charges in the basic cluster, reducing its electrostatic interaction with acidic 
lipids and leading to the translocation of MARCKS from the membrane onto cytoplasm $(14,15)$. Modulating MARCKS expression seems to be mediated by different molecular mechanisms, which may utilize PKC. MARCKS was highly related to $\alpha$-smooth muscle actin ( $\alpha$-SMA), a representative marker of fibrosis in many organs, such as the liver, lungs and heart (16-18). Recent data emphasize the importance of fibrosis, as it is a key factor during the natural progression and development of NAFLD (19). However, the role of MARCKS in high-fat (HF) diet-fed mice with NAFLD and the underlying mechanisms have not yet been fully investigated.

The inflammatory response regulated by NLR family pyrin domain containing 3 (NLRP3) and nuclear factor (NF)- $\mathrm{B}$ has been shown to be associated with NAFLD development through the release of pro-inflammatory cytokines, such as interleukin (IL), IL6 and IL-18 (20,21). Additionally, recent studies on peroxisome proliferator-activated receptor (PPAR) transcription factors found decreased hepatic PPAR $\alpha$ expression accompanied by an increased NASH severity (22-24). Furthermore, following intervention, PPAR $\alpha$ expression is then restored in patients whose liver histology has improved, as with the expression of many of the metabolic target genes of PPAR $\alpha$, including the gene that encodes carnitine palmitoyltransferase- 1 (CPT-1) $\alpha$, a rate limiting enzyme for mitochondrial $\beta$-oxidation $(25,26)$.

In the present study, we investigated the molecular mechanisms through which CA suppresses inflammation and lipogenesis in mice with HF diet-induced NAFLD. We found that the effects of CA are mediated via the regulation of MARCKS expression and related signaling pathways.

\section{Materials and methods}

Animals and reagents. A total of 60 male C57BL/6 mice weighed 18-22 g [used as wild-type (WT) mice] were purchased from the Experimental Animal Center of Nanjing Medical University (Nanjing, China). Thirty MARCKS-deficient mice were purchased from Jackson Laboratory (Bar Harbor, ME, USA). All mice were provided with drinking water, and housed in a controlled environment with a temperature of $22 \pm 2^{\circ} \mathrm{C}$ and relative humidity of $60 \pm 10 \%$ under a 12 -h light/dark cycle. This study was approved by the Ethics Committee on Animal Research at the Department of Otolaryngology-Head and Neck Surgery, Huai'an Hospital Affiliated to Xuzhou Medical College, Huaian, China.

The 90 animals were divided into 6 groups (15 in each group) as follows: i) wild-type mice fed the normal chow diet (WT/Chow); ii) wild-type mice fed the HF diet (WT/ $\mathrm{HF}$ ); iii) MARCKS-knockout mice fed the normal chow diet (MARCKS ${ }^{-/} /$Chow); iv) MARCKS-knockout mice fed the HF diet (MARCKS ${ }^{-/} / \mathrm{HF}$ ); v) wild-type mice fed the HF diet combined with $15 \mathrm{mg} / \mathrm{kg}$ CA (purity $>98 \%$; BioBioPha, Yunnan, China); and vi) wild-type mice fed the HF diet combined with $30 \mathrm{mg} / \mathrm{kg}$ CA. CA was dissolved in distilled water at $0.3 \mathrm{mg} / \mathrm{ml}$ and administered to the mice with free access. Mice given distilled water were used as controls (WT/ Chow and MARCKS ${ }^{-/} /$Chow). CA administration was initiated when the mice were fed with HF diets. Mice were administered a standard diet containing most essential nutrients, such as vitamins A ( $\geq 14,000 \mathrm{IU}), \mathrm{D}(\geq 1,500 \mathrm{IU}), \mathrm{E}$ ( $\geq 120 \mathrm{IU}), \mathrm{K}(\geq 5 \mathrm{mg})$, B1 ( $\geq 13 \mathrm{mg})$, B2 ( $\geq 12 \mathrm{mg})$, B6 ( $\geq 12 \mathrm{mg})$, B12 ( $\geq 0.022 \mathrm{mg})$, biotin ( $\geq 0.2 \mathrm{mg}$ ) and niacin ( $\geq 60 \mathrm{mg}$ ) per $\mathrm{kg}$. During the period of study, the fodder was changed to a HF diet (60 kcal\% fat, D12492; Research Diets, USA) until the mice were sacrificed for further analysis. At the end of week 8, body weight was monitored and all experimental mice were sacrificed after $12 \mathrm{~h}$ of fasting. Eyeball blood was collected, and serum was obtained by centrifugation at $13,000 \mathrm{rpm}$ for $15 \mathrm{~min}$ at $4^{\circ} \mathrm{C}$ and stored at $-80^{\circ} \mathrm{C}$ for analysis. The whole liver tissues were harvested and weighed on a $4^{\circ} \mathrm{C}$ glacial table, and were either frozen in liquid nitrogen and kept at $-80^{\circ} \mathrm{C}$ for analysis, or fixed in $4 \%$ paraformaldehyde for histological analysis. All the methods were carried out in accordance with the approved guidelines.

Oral glucose tolerance test (OGTT) and insulin tolerance test (ITT). At the end of the feeding period, OGTT and ITT were conducted. The mice from the WT/Chow, WT/HF, $\mathrm{MARCKS}^{-/} / \mathrm{HF}$ and $\mathrm{MARCKS}^{-/} /$Chow groups were treated with $20 \%$ glucose dissolved in saline orally or injected with insulin intraperitoneally ( $1 \mathrm{U} / \mathrm{kg}$ body weight). Tail-vein blood was collected at $0,30,60,90$ and $120 \mathrm{~min}$ after glucose or insulin treatment, and centrifuged at $4000 \mathrm{xg}$ for $10 \mathrm{~min}$ at $4^{\circ} \mathrm{C}$ to obtain serum for glucose assay.

Biochemical indicator evaluation. TG, total cholesterol (TC), aspartate transaminase (AST), alanine transaminase (ALT), uric acid and non-esterified fatty acid (NEFA) levels in serum or liver tissue obtained from the WT/Chow, WT/HF, MARCKS ${ }^{-/} / \mathrm{HF}$ and $\mathrm{MARCKS}^{-/} / \mathrm{Chow}$ groups of mice were determined using biochemical kits (Nanjing Jiancheng Biotechnology, Nanjing, China) following the manufaturer's instructions. TG, TC, AST, and ALT in serum or liver from the Con, HF, CAL and CAH groups were measured using biochemical kits.

Serum glucose and serum insulin assays. Mice from the WT/ Chow, WT/HF, MARCKS ${ }^{-/ /} / \mathrm{HF}$, MARCKS $^{-/ /} / \mathrm{Chow}, \mathrm{CAL}$, and $\mathrm{CAH}$ groups were fasted for $6 \mathrm{~h}$, after which their blood was analyzed for glucose measurement with a glucose meter (Bayer, Mishawaka, IN, USA). For insulin analysis, the mice were fasted for $6 \mathrm{~h}$ and plasma insulin levels were measured with an Ultra Sensitive Mouse insulin enzyme-linked immunosorbent assay (ELISA) kit from Crystal Chem (Downers Grove, IL, USA).

ELISA. The serum from 6 groups of mice was analyzed for the levels of major inflammatory cytokines, such as TNF- $\alpha$ (\#MTA00B), IL-6 (\#M6000B), IL-1 $\beta$ (\#MLB00C), IL-18 (\#7625), IL-2 (\#M2000), IL-4 (\#M4000B), IL-6 (\#D6050), IL-12 (\#M1270) and IFN $\gamma$ (\#MIF00), by ELISA, following the manufacturer's instructions (R\&D Systems, Inc., Minneapolis, $\mathrm{MN}, \mathrm{USA})$. Color changes were determined at $450 \mathrm{~nm}$.

Histopathological examination of liver tissues. The tissue isolated from WT/Chow, WT/HF, MARCKS $\mathrm{MAF}^{-/} / \mathrm{HF}$ and MARCKS $^{-/} /$Chow groups of mice were fixed with $10 \%$ buffered formalin, imbedded in paraffin and sliced into $4-5 \mu \mathrm{m}$ thick sections. Following hematoxylin and eosin (H\&E) staining, the pathological changes of the liver tissues were observed under a light microscope. Hepatic lipid content in mice from WT/ Chow, WT/HF, MARCKS ${ }^{-/ /} / \mathrm{HF}, \mathrm{MARCKS}^{-/ /} / \mathrm{Chow}, \mathrm{CAL}$, and $\mathrm{CAH}$ groups was determined using $5-\mu \mathrm{m}$-thick frozen sections 
Table I. Primary antibodies used in western blot analysis .

\begin{tabular}{|c|c|c|}
\hline Primary antibodies & $\begin{array}{l}\text { Dilution } \\
\text { ratio }\end{array}$ & Corporation \\
\hline Rabbit anti-MARCKS (ab51100) & $1: 1,000$ & Abcam \\
\hline Rabbit anti-IL-1 $\beta$ (ab9722) & $1: 1,000$ & Abcam \\
\hline Rabbit anti-IL-18 (ab71495) & $1: 1,000$ & CST \\
\hline Rabbit anti-SREBP-1c (ab28481) & $1: 1,000$ & CST \\
\hline Rabbit anti-FAS (ab82419) & $1: 1,000$ & Abcam \\
\hline Rabbit anti-NF-кB (ab207297) & $1: 1,000$ & Abcam \\
\hline Mouse anti-p-NF- $\kappa B$ (3033) & $1: 1,000$ & CST \\
\hline Rabbit anti-caspase-1 (ab1872) & $1: 1,000$ & Abcam \\
\hline Rabbit anti-PPAR $\alpha$ (ab8934) & $1: 1,000$ & Abcam \\
\hline Rabbit anti-PI3K (ab189403) & $1: 1,000$ & Abcam \\
\hline Mouse anti-p-AKT (9611) & $1: 1,000$ & CST \\
\hline Rabbit anti-AKT (ab182729) & $1: 1,000$ & Abcam \\
\hline Rabbit anti-NLRP3 (ab214185) & $1: 1,000$ & Abcam \\
\hline Mouse anti-ACC $\alpha$ (sc-137104) & $1: 200$ & Santa Cruz \\
\hline Mouse anti-SCD1 (sc-515844) & $1: 200$ & Santa Cruz \\
\hline GAPDH (sc-51631) & $1: 200$ & Santa Cruz \\
\hline
\end{tabular}

MARCKS, myristoylated alanine-rich C-kinase substrate; IL, interleukin SREBP-1c, sterol regulatory element binding protein-1c; NF- $k B$, nuclear factor- $\kappa \mathrm{B}$; PPAR $\alpha$, peroxisome proliferator-activated receptor $\alpha ; \mathrm{PI} 3 \mathrm{~K}$, phosphoinositide 3-kinase; NLRP3, NLR family pyrin domain containing 3; GAPDH, glyceraldehyde 3-phosphate dehydrogenase. CST, Cell Signaling Technology; Santa Cruz, Santa Cruz Biotechnology.

stained with Oil Red O (Sigma-Aldrich). Masson's trichrome staining was performed according to the manufacturer's instructions (Diagnostic Biosystems Inc., Pleasanton, CA, USA). In addition, some tissues also were subjected to immunohistochemical (IHC) staining for the analysis of MARCKS (except for $\mathrm{MARCKS}^{-/} / \mathrm{HF}$ and $\mathrm{MARCKS}^{-/} /$Chow groups) and PPAR $\alpha$ from each group of mice expression. The sections were stained with MARCKS (ab51100; Abcam, Shanghai, China) and PPAR $\alpha$ (ab8934; Abcam). All histological examinations were carried out according to standard procedures reported previously (27). Furthermore, immunofluorescence assays for PPAR $\alpha$ for liver tissue were performed according to the manufacturer's instructions.

Western blot analysis. The liver tumors were homogenized into $10 \%$ (wt/vol) hypotonic buffer (pH 8.0, 1 mM EDTA, $5 \mu \mathrm{g} /$ $\mathrm{ml}$ leupeptin, $25 \mathrm{mM}$ Tris- $\mathrm{HCl}, 1 \mathrm{mM}$ Pefabloc SC, $5 \mu \mathrm{g} / \mathrm{ml}$ soybean trypsin inhibitor, $50 \mu \mathrm{g} / \mathrm{ml}$ aprotinin, $4 \mathrm{mM}$ benzamidine) to yield a homogenate. Primary antibodies were shown in Table I. The final supernatants from cells and tumors were then obtained by centrifugation at $14,000 \mathrm{x} \mathrm{g}$ for $20 \mathrm{~min}$ at $4^{\circ} \mathrm{C}$. The protein concentration was determined using a BCA protein assay kit (Thermo Fisher Scientific, Inc., Waltham, MA, USA) with bovine serum albumin as a standard. Sampleloading buffer was added, the mixture was boiled for $5 \mathrm{~min}$. And the total protein extract was used for western blot analysis. Total protein $(40 \mu \mathrm{g})$ was loaded and proteins were separated using $10 \%$ SDS-PAGE and electrophoretically transferred to the polyvinylidene difluoride membranes (Millipore, Billerica,
MA, USA). The membranes were then blocked with 5\% skim milk Tris-buffered saline with $0.1 \%$ Tween 20 (TBST), washed, and then incubated with primary antibodies overnight at $4^{\circ} \mathrm{C}$. The membrane was then washed with TBST 3 times, followed by incubation with a horseradish peroxidase (HRP)-conjugated secondary antibody (1:2,500; KeyGen Biotech, Nanjing, China) at room temperature for $2 \mathrm{~h}$. Following another round of washing with TBST, the membrane was then developed using ECL (Thermo Fisher Scientific, Inc.), and exposed to Kodak X-ray film (Eastman Kodak Company, Rochester, NY, USA). Every protein expression level was defined as grey value using ImageJ 1.38 software (National Institutes of Health, Bethesda, MD, USA) and standardized to housekeeping gene of GAPDH and expressed as a fold of control. All experiments were performed in triplicate and done three times independently.

Reverse transcription-quantitative PCR (RT-qPCR). For analysis of qPCR, was performed as previously described (28). Total RNA was extracted from liver tissues using TRI-Reagent (SigmaAldrich) following the manufacturer's instructions and treated with deoxyribonuclease I. First-strand cDNA was then synthesized and amplified from $0.5 \mu \mathrm{g}$ of total RNA using the ReverTra Ace qPCR RT kit (Toyobo, Tokyo, Japan). Real-time PCR was carried out for 35 cycles of $95^{\circ} \mathrm{C}$ for $20 \mathrm{sec}, 54^{\circ} \mathrm{C}$ for $30 \mathrm{sec}$, and $72^{\circ} \mathrm{C}$ for $30 \mathrm{sec}$ using SYBR Green Real-time PCR Master Mix (PE Applied Biosystems, Foster City, CA, USA) in a total volume of $20 \mu \mathrm{l}$. Fold changes in mRNA levels of target gene relative to the endogenous cyclophilin control were calculated. Briefly, the cycle threshold $(=\mathrm{Ct})$ values of each target gene were subtracted from the $\mathrm{Ct}$ values of the housekeeping genecy clophilin $(\Delta \mathrm{Ct})$. Target gene $\Delta \Delta \mathrm{Ct}$ was calculated as $\Delta \mathrm{Ct}$ of target gene minus $\Delta \mathrm{Ct}$ of control. The fold change in mRNA expression was calculated as $2^{-\Delta \Delta \mathrm{Ct}}$. The primers used in the study were showed in Table II.

qPCR analysis was performed as previously described (23). Fold induction values were calculated using the to $2^{-\Delta \Delta \mathrm{Cq}}$ method, where $\Delta \mathrm{Cq}$ represents the differences in cycle threshold number between the target gene and glyceraldehyde 3-phosphate dehydrogenase (GAPDH), and $\Delta \Delta \mathrm{Cq}$ represents the relative change in the differences between the control and treatment groups. The primers used in this study are listed in Table II.

Statistical analysis. Data are expressed as the means \pm SD. The treated cells, tissues and corresponding controls were compared using GraphPad PRI SM (version 6.0; GraphPad Software, Inc., La Jolla, CA, USA) by a one-way ANOVA with Dunn's least significant difference tests or Student's t-tests. Differences between groups were considered significant at $\mathrm{p}<0.05$.

\section{Results}

MARCKS deficiency accelerates liver injury and lipid accumulation in response to being fed a HF diet. At the end of the experimental period, there was a striking difference in liver morphology in the Chow group compared to the high-fat diet feeding mice (Fig. 1A). As shown in Fig. 1A, the mice with MARCKS exhibited more severe liver injury. Significantly, the livers from the HF diet-fed MARCKS-deficient mice were pale in color, suggesting the evident accumulation of liver lipids in comparison to the HF diet-fed wild-type mice. Based on the liver morphology, we hypothesized that MARCKS might 
Table II. Sequences of primers used for RT-qPCR analysis.

\begin{tabular}{lll}
\hline Gene & \multicolumn{1}{c}{ Forward primers $\left(5^{\prime} \rightarrow 3^{\prime}\right)$} & \multicolumn{1}{c}{ Reverse primers $\left(5^{\prime} \rightarrow 3^{\prime}\right)$} \\
\hline GAPDH & CATTCAAGACCGGACAGAGG & ACATACTCAGCACCAGCATCACC \\
MARCKS & AGCACAAAGAGAGTGTCGC & CGTCAGTCAGTGTGTATG \\
IL-1 $\beta$ & GACAGCAAAGTGATAGGCC & CGTCGGCAATGTATGTGTTGG \\
IL-18 & GCAGCAGGTGAGTGGGCAGT & CTGTACGCCTGGTTCGCTCTGT \\
IL-2 & CATGCTGGGGCCGTACAG & TTGTCCGACCTTTGGCAA CT \\
IL-4 & CAGAAGGAAGTTAGGCC & CGTCGCAGTGGATGATGTG \\
IL-12 & CTTCTCACTGTCGACTACCGC & GCGTC TCCTGTGCATTCG \\
IFN- $\gamma$ & GACTCTTCCTGGTCTTACCATATT & CTGCTATTGCAAGGACCCAATT \\
\hline
\end{tabular}

MARCKS, myristoylated alanine-rich C-kinase substrate; GAPDH, glyceraldehyde 3-phosphate dehydrogenase; TNF- $\alpha$, tumor necrosis factor- $\alpha$; IL, interleukin; IFN- $\gamma$, interferon- $\gamma$.
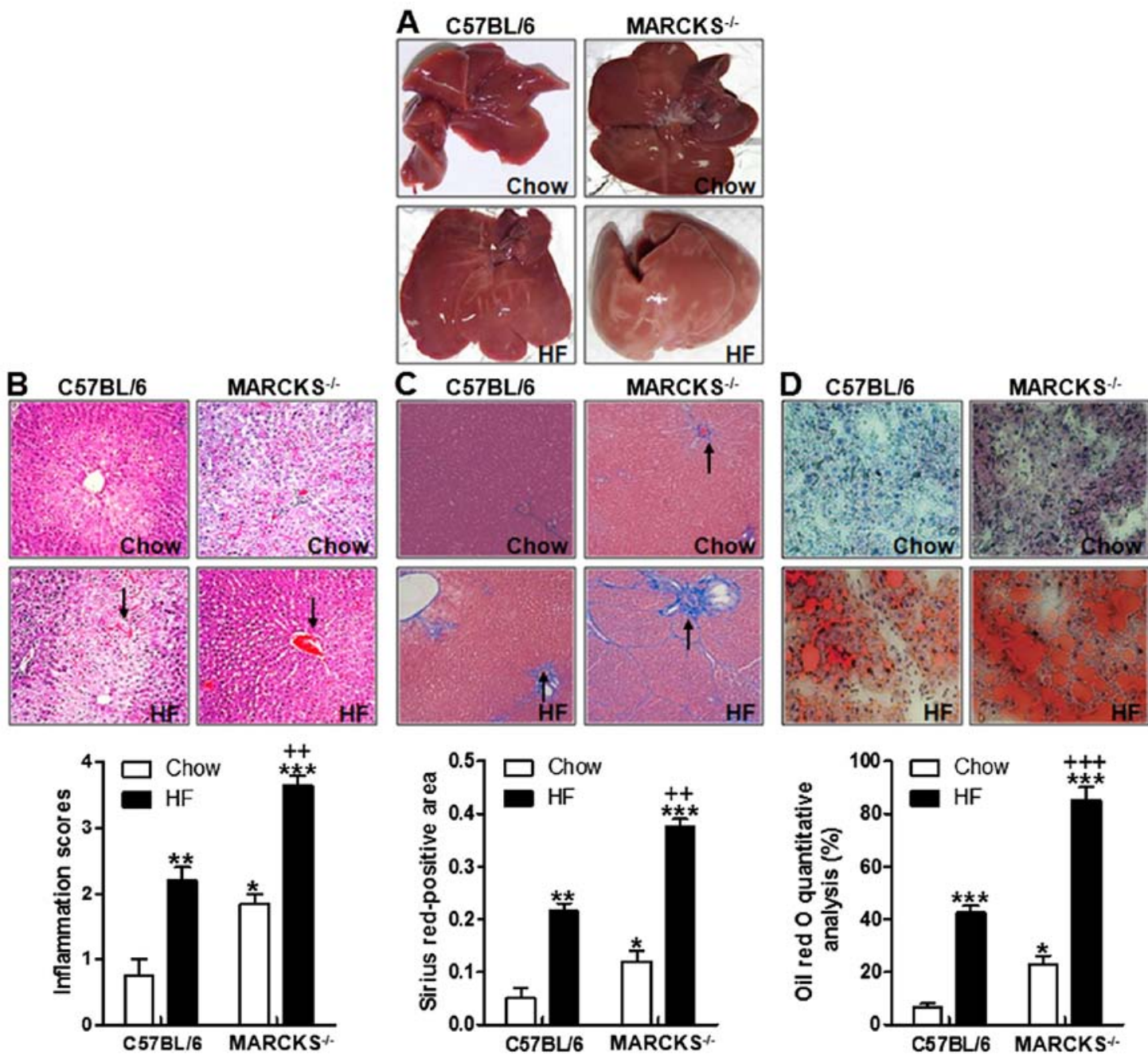

Figure 1. Myristoylated alanine-rich C-kinase substrate (MARCKS)-deficiency accelerates liver injury and lipid accumulation in response to a high-fat (HF) diet. (A) Liver gross morphology. (B) Liver sections stained with hematoxylin and eosin (H\&E). (C) Sirius Red staining for liver fibrosis. (D) Liver histology as determined by Oil Red O staining. Results are the means \pm SD of 8 mice/group. ${ }^{*} p<0.05,{ }^{* *} \mathrm{p}<0.01$ and ${ }^{* * * *} \mathrm{p}<0.001$ vs. the C57BL/6-chow group; ${ }^{++} \mathrm{p}<0.01$ and ${ }^{+++} \mathrm{p}<0.001$ vs. the C57BL/6-HF group.

have a potential role in regulating lipid accumulation in the liver. Additionally, the results of $\mathrm{H} \& \mathrm{E}$ staining revealed that liver injury was induced in the HF diet-fed wild-type mice compared with the mice fed the normal chow. Importantly, the liver inflammation score was the highest in the HF dietfed MARCKS-deficient mice (Fig. 1B). These data indicated 

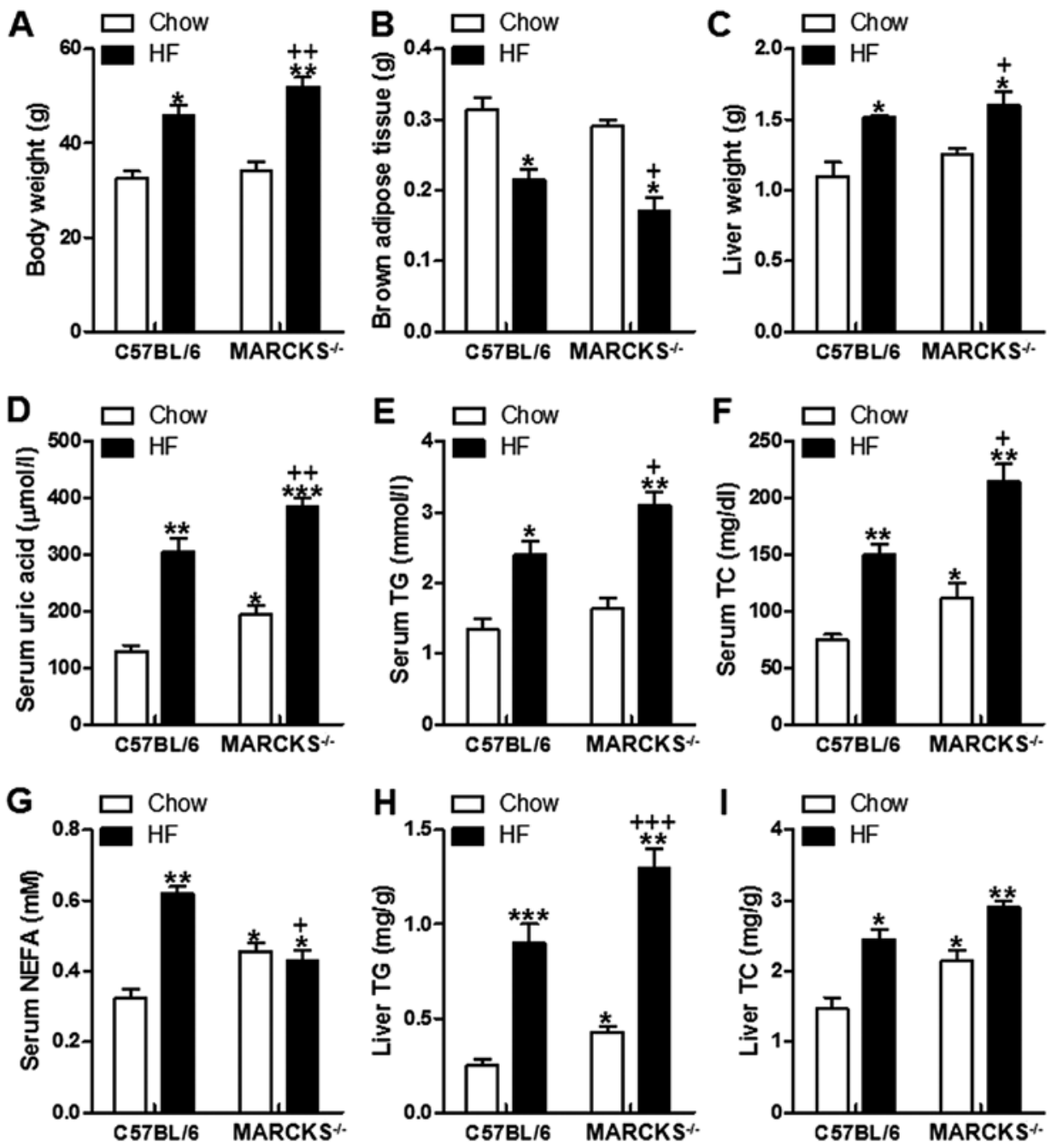

Figure 2. High-fat (HF) diet-induced liver lipid accumulation is accelerated in myristoylated alanine-rich C-kinase substrate (MARCKS)-deficient mice. (A) Body weight was determined in the different groups. (B) Brown tissue weight was calculated. (C) Liver weight was evaluated. (D) Serum uric acid levels were measured. Serum (E) triglyceride (TG), (F) total cholesterol (TC) and (G) non-esterified fatty acid (NEFA) levels were calculated. Liver (H) TG and (I) TC levels were measured. Results are the means \pm SD of 8 mice/group. ${ }^{*} \mathrm{p}<0.05,{ }^{* *} \mathrm{p}<0.01$ and ${ }^{* * * *} \mathrm{p}<0.001 \mathrm{vs}$. the $\mathrm{C} 57 \mathrm{BL} / 6$-chow group; ${ }^{+} \mathrm{p}<0.05$ and ${ }^{++} \mathrm{p}<0.01 \mathrm{vs}$. the C57BL/6-high fat (HF) diet group.

MARCKS may be of great importance in preventing liver injury induced by HF. Similarly, Masson's Trichrome staining indicated that liver fibrosis was mildly increased in wild-type, but more robustly increased in $\mathrm{MARCKS}^{-/-}$mice responding to HF diet (Fig. 1C). Indeed, the number of lipid droplets were also higher in the HF diet-fed wild-type mice compared with the normal chow-fed mice. However, an even higher number of lipid droplets was observed in the livers of the MARCKSdeficient mice fed the HF diet (Fig. 1D). These data indicated that MARCKS deficiency promoted liver injury and liver lipid accumulation in mice fed with HF diet.

HF diet-induced liver lipid accumulation is accelerated in MARCKS-deficient mice. We measured the body weight at the end of the experimental period. As shown in Fig. 2A, body weight was increased in the wild-type mice fed the HF diet compared with those fed the normal chow. MARCKS deficiency increased the body weight of the HF diet-fed mice even further (Fig. 2A). The brown adipose tissue weight was decreased in the HF diet-fed mice, and this was further decreased in the MARCKSdeficient mice fed with HF (Fig. 2B). In addition, liver weight was increased in the wild-type mice in response to the HF diet, and an even greater increase was observed in the MARCKSdeficient mice fed the HF diet (Fig. 2C). Similarly, serum uric acid was highly increased in wild-type mice induced by HF. In the MARCKS-deficient mice, the uric acid levels were even higher than those of the wild-type mice fed the HF diet (Fig. 2D). The HF diet-fed wild-type mice also exhibited significantly higher serum levels of TGs, TC and NEFA than the chow diet-fed wild-type mice. The mice with MARCKS deficiency fed the HF diet exhibited even higher levels of serum TGs, TC and NEFA (Fig. 2E-G). Consistent with the serum alterations, the hepatic TG and TC contents were significantly higher in the HF diet-fed wild-type mice compared with the chow dietfed wild-type mice. The MARCKS-deficient mice fed the HF diet exhibited even higher TG and TC (Fig. 2H and I). These results indicated that MARCKS deficiency intensified the HF diet-induced accumulation of TGs and TC.

MARCKS deficiency disrupts glucose homeostasis, and promotes insulin resistance and liver injury. We then determined whether MARCKS deficiency is is involved in glucose 

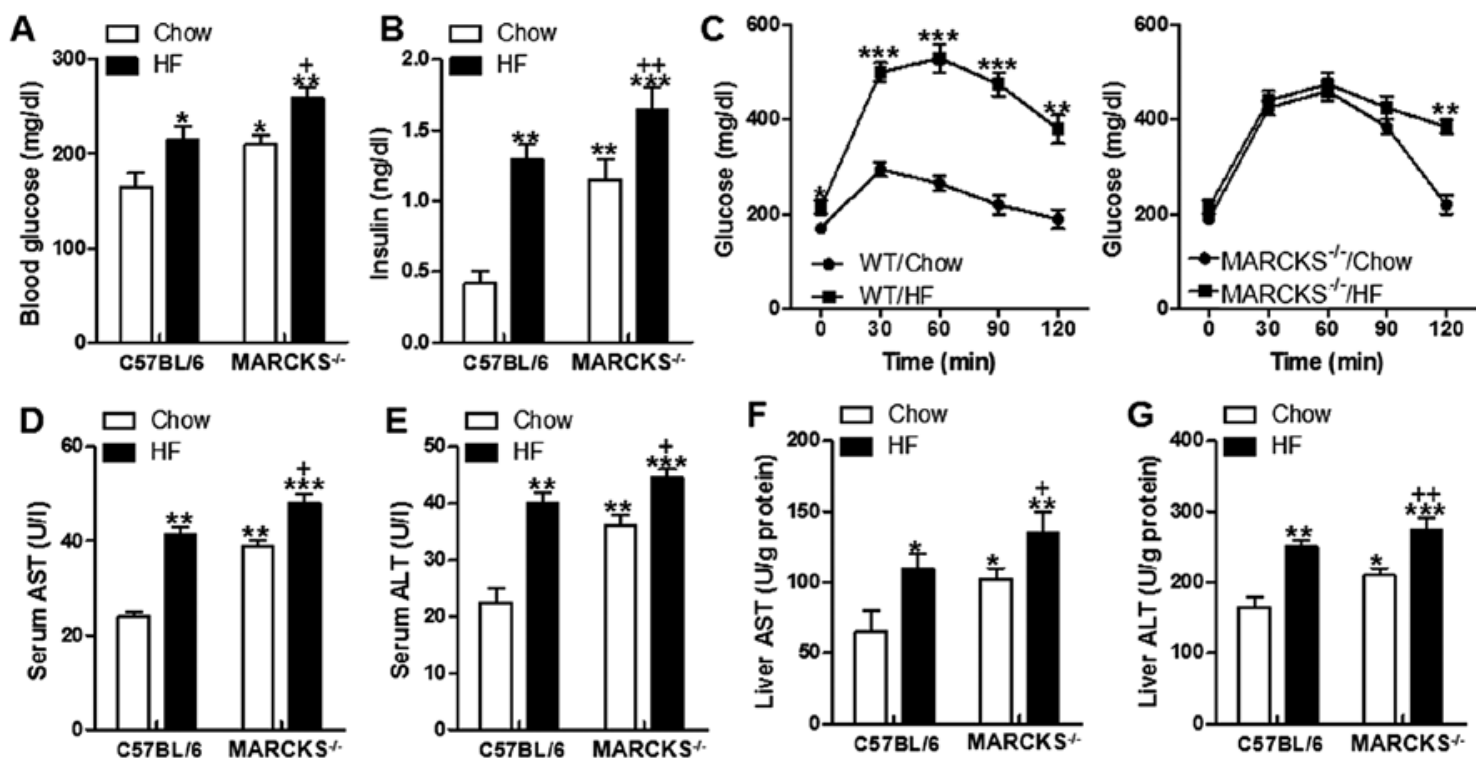

Figure 3. Myristoylated alanine-rich C-kinase substrate (MARCKS) deficiency disrupts glucose homeostasis, insulin resistance and promotes liver injury. (A) Serum glucose levels. (B) Serum insulin levels. (C) Glucose tolerance test (GTT). Serum (D) aspartate transaminase (AST) and (E) alanine transaminase (ALT) activities were measured in plasma. Liver (F) AST and (G) ALT levels were measured. Results are the means \pm SD of 8 mice/group. ${ }^{*} p<0.05,{ }^{* *} p<0.01$ and ${ }^{* * *} \mathrm{p}<0.001$ vs. the C57BL/6-chow group; ${ }^{+} \mathrm{p}<0.05$ and ${ }^{++} \mathrm{p}<0.01$ vs. the $\mathrm{C} 57 \mathrm{BL} / 6$-high fat (HF) diet group.

and insulin resistance in HF diet-fed mice. The fasting blood glucose levels and serum insulin levels were increased in HF-fed mice, which was robustly upregulated in responding to MARCKS deficiency (Fig. 3A and B). We then performed a glucose tolerance test. Consistent with their elevated fasting glucose and insulin concentrations on the chow diet, MARCKS ${ }^{-1}$ mice were more glucose intolerant than the mice on chow diet (Fig. 3C). The mice exhibited increased AST and ALT in serum as well as the increased concentrations of hepatic AST and ALT after HF diet (Fig. 3D-G). The MARCKS-deficient mice had even higher AST and ALT levels in serum and in the liver tissues, particularly those fed the HF diet (Fig. 3D-G).

MARCKS deficiency induces pro-inflammatory cytokine secretion in vivo. HF diet-induced liver injury is always associated with inflammation (29). Thus, in this regard, we evaluated pro-inflammatory cytokine expression. The data indicated that the expression levels of IL-1 $\beta$, IL-18, TNF- $\alpha$, IL-2, IL-4, IL-6, IL-12 and IFN- $\gamma$ in serum were markedly increased in mice fed the HF diet compared to those fed the normal chow diet. The MARCKS-deficient mice fed the HF diet exhibited even further upregulated levels of these pro-inflammatory cytokines (Fig. 4A-H). To further confirm these results, we also measured the pro-inflammatory cytokine levels in liver tissue samples by RT-qPCR. The results revealed that the hepatic mRNA levels of IL-1 $\beta$, IL-18, TNF- $\alpha$, IL-2, IL-4, IL-6, IL-12 and IFN- $\gamma$ were elevated in the HF diet-fed mice, and MARCKS deficiency further stimulated these genes expressions (Fig. 4I). These data indicated that the presence of MARCKS greatly attenuated inflammation in liver of mice fed with HF diet.

MARCKS deficiency impairs PI3K/AKT and NLRP3 inflammasome signaling in vivo. As previously demonstrated, the PI3K/AKT signaling pathway is regulated by MARCKS (30). Hence, we attempted to explore whether
MARCKS could regulate NAFLD in mice induced by high fat diet through regulating PI3K/AKT. Western blot analysis was performed to examine the levels of PI3K/AKT. As shown in Fig. 5A, we found that the PI3K/AKT signaling pathway was upregulated in the wild-type mice fed the HF diet. MARCKS deficiency further stimulated PI3K and phosphorylated AKT. AKT has a close association with the NLRP3-regulated NF- $\mathrm{BB}$ signaling pathway (31). As shown in Fig. 5B, NLRP3 expression was upregulated in the HF-fed wild-type mice and in the MARCKS-deficient mice. Subsequently, NF- $\kappa B$ was activated through caspase-1 stimulation in the HF diet-fed wild-type mice, and this was further enhanced by MARCKS deficiency (Fig. 5B and C). NF- $\kappa$ B activation is responsible for the release of pro-inflammatory cytokines, including IL-1 $\beta$ and IL-18 (32). In this study, both IL-1 $\beta$ and IL-18 were highly expressed in the HF diet-fed mice, particularly in the MARCKS-deficient mice (Fig. 5C). These data indicated that MARCKS, consistent with previous results (33), may play a potential role in suppressing the inflammatory response via the PI3K/AKT and NLRP3 inflammasome signaling pathways.

MARCKS deficiency enhances lipogenesis-related signaling pathway activation. NAFLD development has a close association with lipogenesis-related proteins. SREBP-1c, ACC $\alpha$, FAS and SCD1 have been well known to play a crucial role in lipid generation (34-36). We thus then attempted to investigate the mechanisms through which MARCKS regulates lipid metabolism via these proteins. As shown in Fig. 6A, SREBP-1c was highly expressed in HF diet fed mice, something that was consistent with a previous report (37). Similarly, the levels of ACC $\alpha$, FAS and SCD1 were also elevated in the mice fed the HF diet. Of note, MARCKS deficiency markedly increased these proteins levels even further (Fig. 6A). PPARa is known as an important factor regulating lipid metabolism (38). In this study, we found that PPAR $\alpha$ was expressed at low levels in the HF-fed 

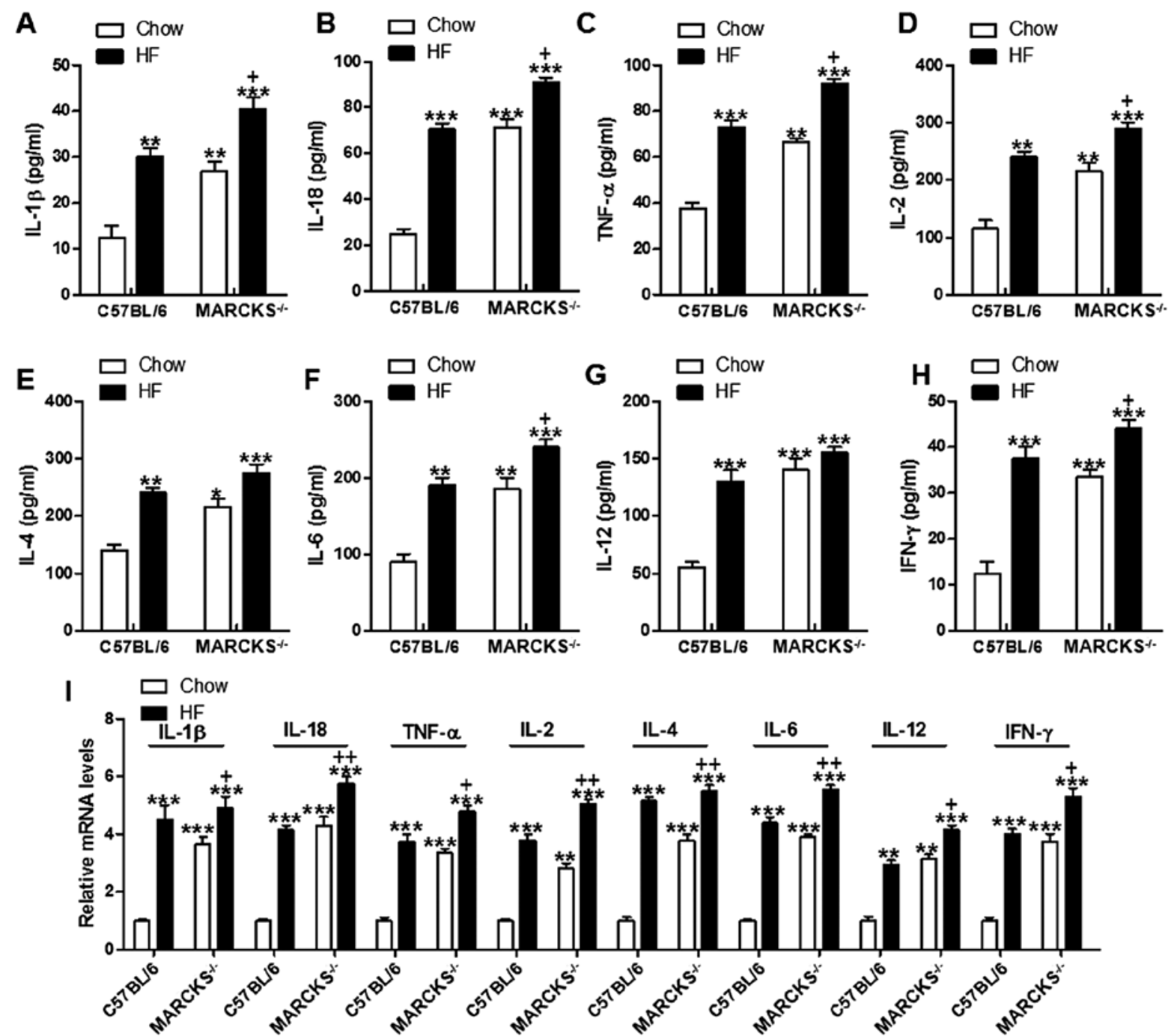

Figure 4. Myristoylated alanine-rich C-kinase substrate (MARCKS) deficiency induces pro-inflammatory cytokine secretion in vivo. Serum (A) interleukin (IL)$1 \beta$, (B) IL-18, (C) tumor necrosis factor- $\alpha$ (TNF- $\alpha$ ), (D) IL-2, (E) IL-4, (F) IL-6, (G) IL-12, and (H) interferon- $\gamma$ (IFN- $\gamma$ ) levels were determined by insulin enzyme-linked immunosorbent assay (ELISA). (I) mRNA levels in liver tissue samples were calculated by RT-qPCR assays. Results are the means \pm SD of 8 mice/group. ${ }^{*} \mathrm{p}<0.05,{ }^{* *} \mathrm{p}<0.01$ and ${ }^{* * *} \mathrm{p}<0.001$ vs. the C57BL/6-chow group; ${ }^{+} \mathrm{p}<0.05$ and ${ }^{++} \mathrm{p}<0.01$ vs. the C57BL/6-high fat (HF) diet group.

mice. MARCKS deficiency even further downregulated PPAR $\alpha$ levels in the HF diet-fed mice (Fig. 6B). Consistently, the results of western blot analysis further proved the PPAR $\alpha$ alterations in the MARCKS-deficient mice fed the HF diet (Fig. 6C). These data suggested that MARCKS may be associated with lipid metabolism in HF diet-fed mice, which influenced NAFLD development.

CA treatment attenuates liver injury in the livers of mice fed the HF diet. We then attempted to reveal how CA affects NAFLD induced by a HF diet in mice. At the end of the treatment period, the H\&E staining results showed that the higher inflammatory score in HF-treated mouse, the livers were much larger. By contrast, a lower inflammatory score was observed in the livers of mice treated with CA (Fig. 7A). Furthermore, Oil Red $\mathrm{O}$ staining results showed that the lipid droplets in livers of mice with HF diet were much larger. By contrast, fewer lipid droplets were observed in the livers of mice treated with CA in a dose-dependent manner (Fig. 5B). As mentioned above, MARCKS has a potential role in regulating HF diet-induced
NAFLD. Thus, we performed immunohistochemical assays and the results indicated that a high number of MARCKSpositive cells was observed in the control group; however, only a few MARCKS-positive cells were observed in the HF diet-fed mice. This number was increased by CA treatment (Fig. 7C). These data indicated that CA prevented liver injury and increased MARCKS expression in the livers of mice fed the HF diet.

HF diet-induced liver lipid accumulation is attenuated by $C A$ in mice. The TG and TC levels in serum were markedly increased following feeding on the HF diet, consistent with the results mentioned above; however, these levels were reduced in the HF diet-fed mice treated with CA (Fig. 8A and B). In addition, TG and TC contents in liver induced by HF diet were significantly decreased for CA administration in a dosedependent manner (Fig. 8C and D). We then examined whether treatment with $\mathrm{CA}$ improves glucose and insulin tolerance in the HF-fed mice. The fasting blood glucose levels and the plasma insulin levels were decreased following treatment with 
A Chow HF Chow HF
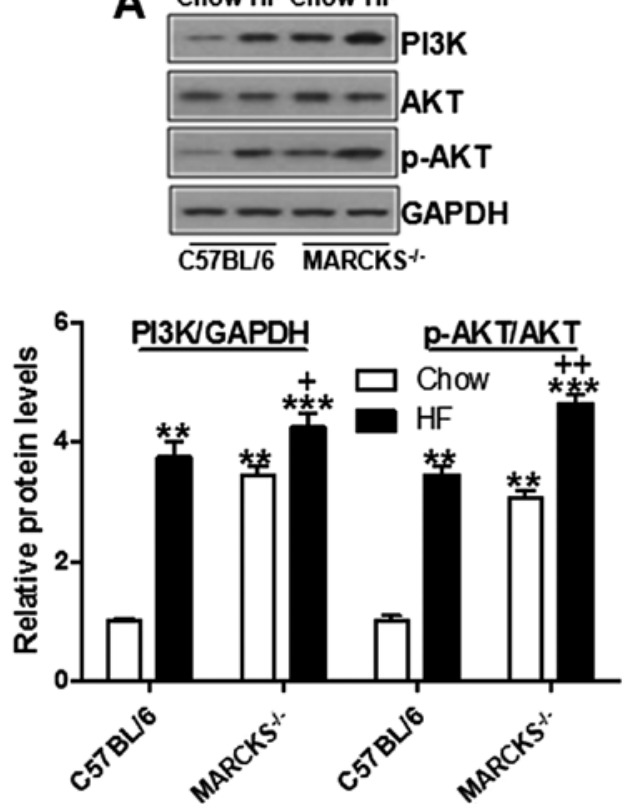

B
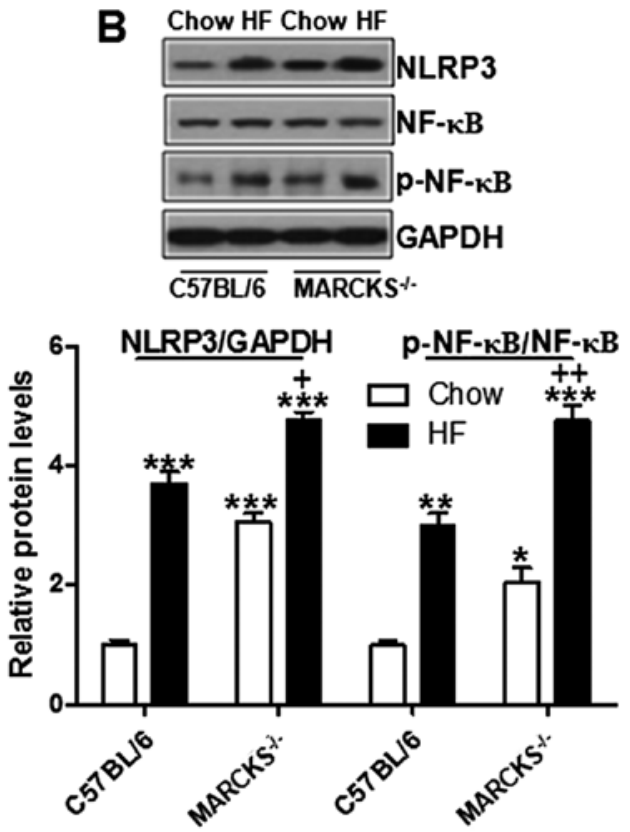
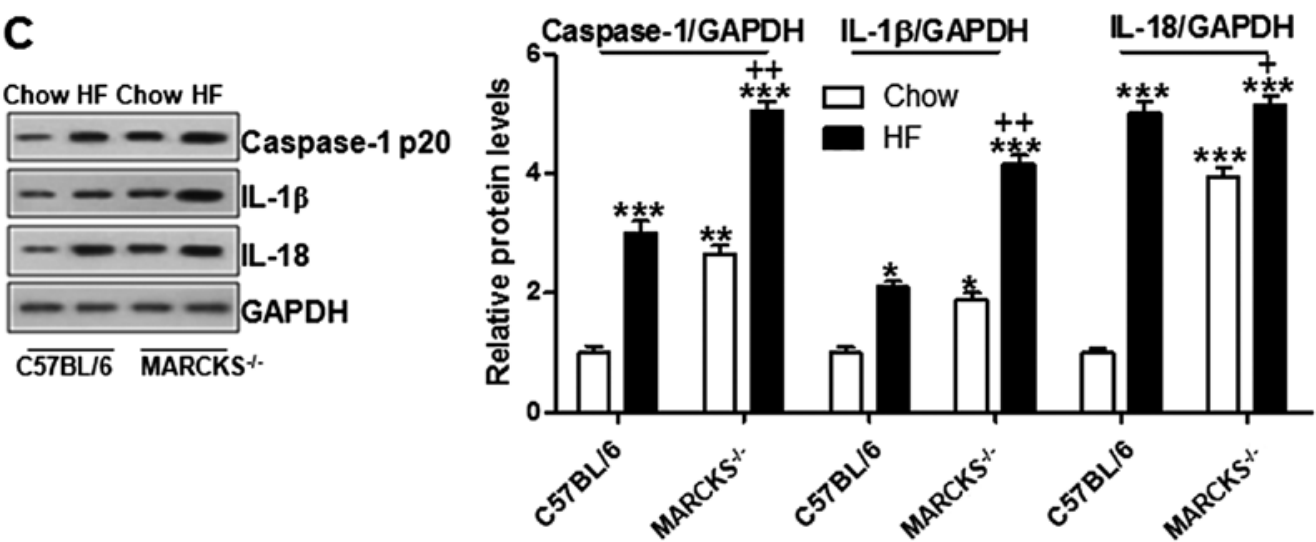

Figure 5. Myristoylated alanine-rich C-kinase substrate (MARCKS) deficiency impairs PI3K/AKT and NLRP3 inflammasome signaling in vivo. (A) Representative western blots of PI3K, and phosphorylated AKT. (B) Representative western blots of NLRP3 and phosphorylated nuclear factor- $\mathrm{kB}$ (NF- $\mathrm{kB}$ ). (C) Representative western blots of caspase-1, interleukin (IL)-1 $\beta$ and IL-18. Results are the means \pm SD of 8 mice/group. ${ }^{*} p<0.05,{ }^{* *} p<0.01$ and ${ }^{* * * *} \mathrm{p}<0.001$ vs. the C57BL/6-chow group; ${ }^{+} \mathrm{p}<0.05$ and ${ }^{++} \mathrm{p}<0.01$ vs. the C57BL/6-high fat (HF) diet group.

CA (Fig. 8E and F). Additionally, the serum AST and ALT levels were upregulated in the HF diet-fed mice, and were downregulated following treatment with CA (Fig. 8G and H). Similarly, the hepatic AST and ALT contents were also increased in HF groups compared to that in the Con group, which were decreased in HF diet-fed mice treated with CA (Fig. 8I and J). These results clearly indicated that CA treatment suppressed lipid accumulation by reducing TG and TC in serum and in liver, improving liver injury in mice administered with high fat diet.

$C A$ reduces pro-inflammatory cytokine expression in mice fed a $H F$ diet. Accelerated NAFLD is often associated with the increased production of inflammatory cytokines (39). Therefore, in this study, we examined whether CA represses the productions of inflammatory cytokines. To examine this, we evaluated the expression levels of the inflammatory cytokines, IL-1 $\beta$, IL-18, TNF- $\alpha$, IL-2, IL-4, IL-6, IL-12 and IFN- $\gamma$, in serum. The data indicated that the expression levels of IL-1 $\beta$, IL-18, TNF- $\alpha$, IL-2, IL-4, IL-6, IL-12 and IFN- $\gamma$, which had been increased by the HF diet, were markedly decreased by CA in the mice fed the HF diet (Fig. 9A). As can be seen in Fig. 9B, CA suppressed pro-inflammatory cytokines release through RT-qPCR analysis (Fig. 9B). These data indicated that treatment with CA markedly attenuated inflammation in mice fed a HF diet.

CA increases MARCKS expression in mice fed a HF diet. To elucidate the precise mechanisms responsible for the effects of CA in HF diet fed-mice and explore whether it can target MARCKS to attenuate NAFLD, we examined MARCKS expressed levels. The results revealed that the MARCKS levels were affected by the administration of CA in the HF diet-fed mice. MARCKS protein levels, which had been decreased by the HF diet, were markedly increased by CA (Fig. 10A). The mRNA level of MARCKS was also decreased in the HF diet-fed mice, and this reduction was reversed significantly following treatment with CA (Fig. 10B). To further examine this, we performed immunostaining using an antibody against MARCKS. Our results revealed that a great number of MARCKS-positive 
A

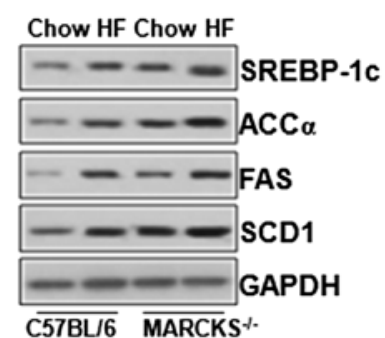

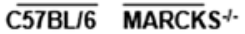

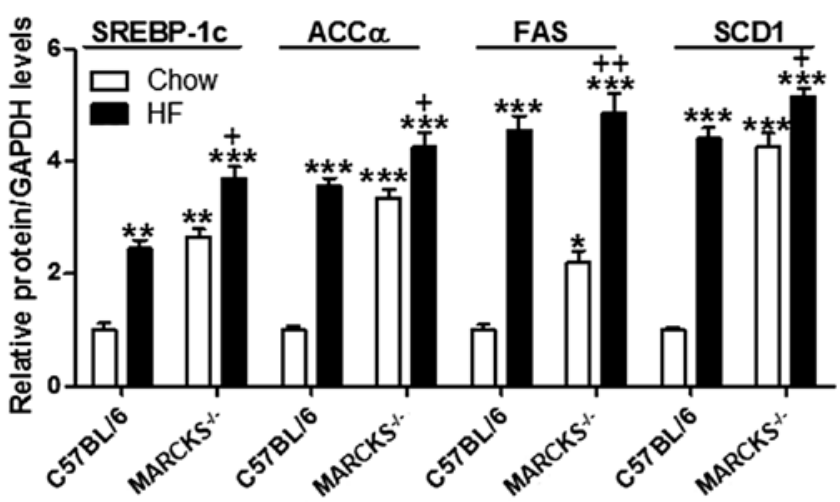

B

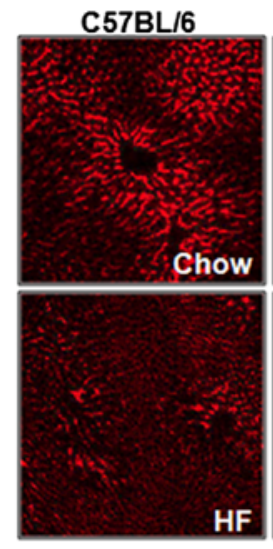

MARKS - -
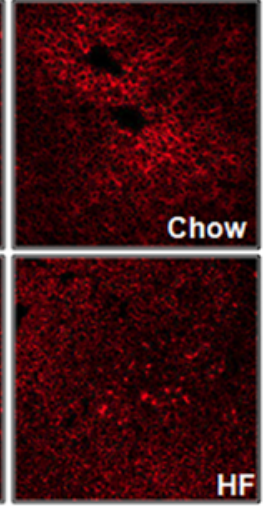

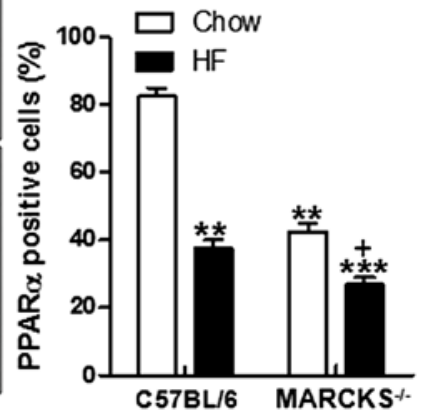

C Chow HF Chow HF
PPAR

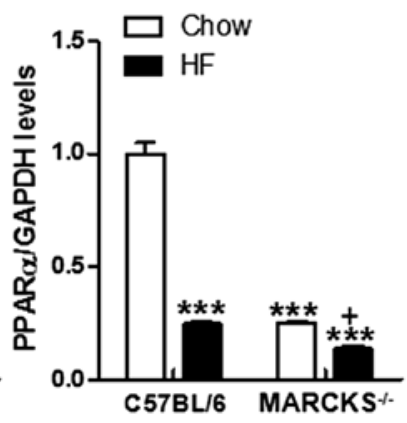

Figure 6. Myristoylated alanine-rich C-kinase substrate (MARCKS) deficiency enhances lipogenesis-related signaling pathway activation. (A) Representative western blots of SREBP-1c, ACC $\alpha$, FAS and SCD1. (B) Immunofluorescence analysis of PPAR $\alpha$ in the liver tissue samples of mice. (C) Representative western blots of PPAR $\alpha$ protein levels. Results are the means \pm SD of 8 mice/group. ${ }^{*} \mathrm{p}<0.05,{ }^{* *} \mathrm{p}<0.01$ and ${ }^{* * *} \mathrm{p}<0.001$ vs. the C57BL/6-chow group; ${ }^{++} \mathrm{p}<0.01$ and ${ }^{+++} \mathrm{p}<0.001$ vs. the C57BL/6-high fat (HF) diet group.

A
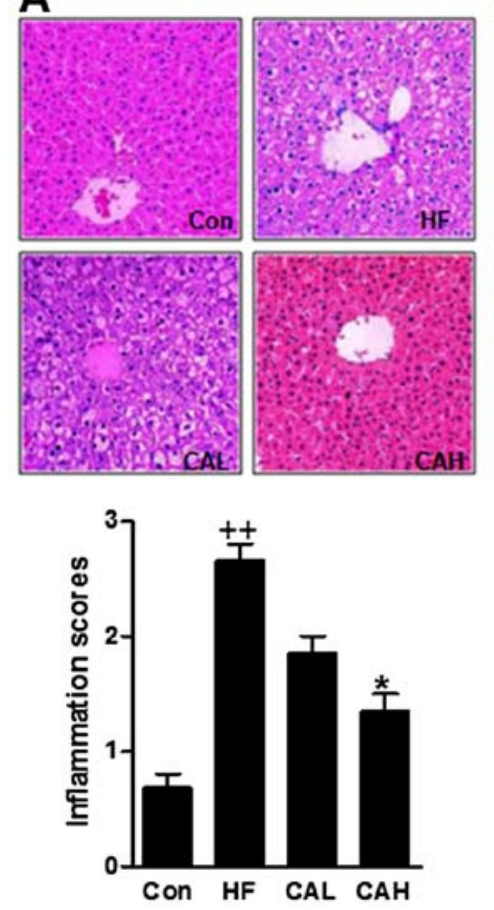

B
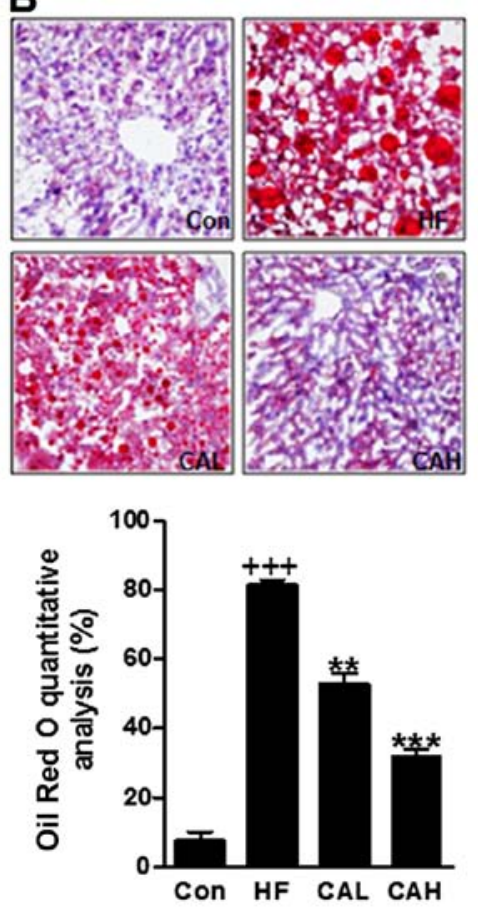

C
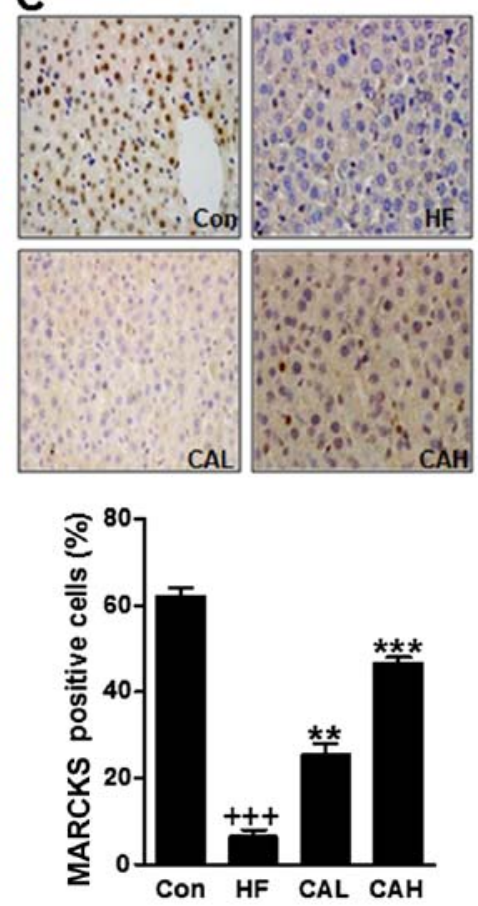

Figure 7. Carnosic acid treatment attenuates liver injury in livers of mice fed a high-fat (HF) diet. (A) Liver sections stained with hematoxylin and eosin (H\&E). (B) Liver histology as determined by Oil Red O staining. (C) Liver Myristoylated alanine-rich C-kinase substrate (MARCKS) levels in mice fed a HF after carnosic acid administration. Results are the means \pm SD of 8 mice/group. ${ }^{++} \mathrm{p}<0.01$ and ${ }^{+++} \mathrm{p}<0.001$ vs. the Con group; ${ }^{*} \mathrm{p}<0.05,{ }^{* *} \mathrm{p}<0.01$ and ${ }^{* * *} \mathrm{p}<0.001$ vs. the HF group. 

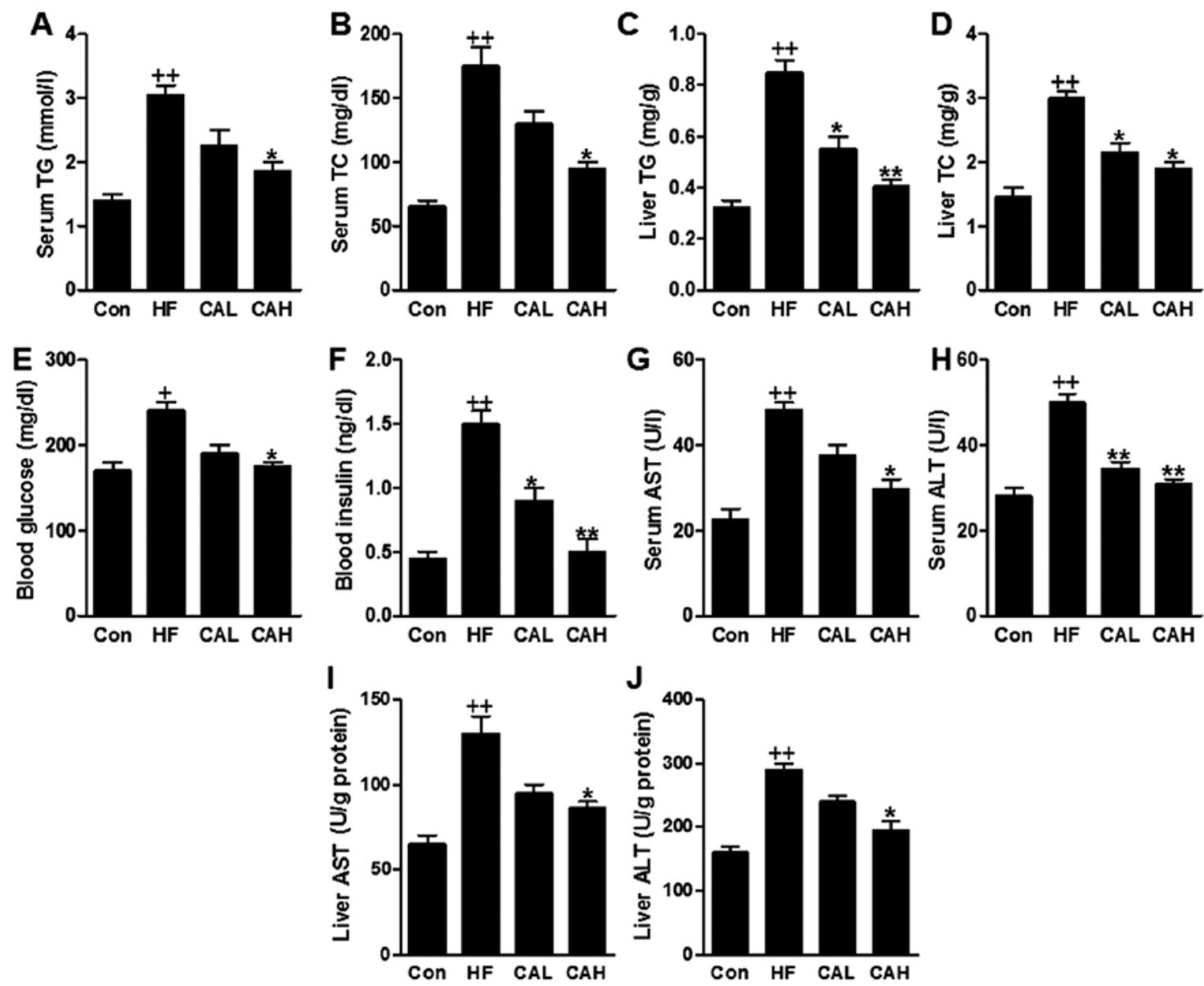

Figure 8. High-fat (HF) diet-induced liver lipid accumulation is attenuated by carnosic acid in mice. Serum (A) triglyceride (TG), and (B) total cholesterol (TC) levels were calculated in mice after carnosic acid administration. Liver (C) TG and (D) TC levels were measured. (E) Plasma glucose levels. (F) Plasma insulin levels. Serum (G) aspartate transaminase (AST) and (H) alanine transaminase (ALT) activities were measured. Liver (I) AST and (J) ALT levels were determined. Results are the means $\pm \mathrm{SD}$ of 8 mice/group. ${ }^{+} \mathrm{p}<0.05$ and ${ }^{++} \mathrm{p}<0.01$ vs. the Con group; ${ }^{*} \mathrm{p}<0.05,{ }^{* *} \mathrm{p}<0.01$ vs. the HF group.
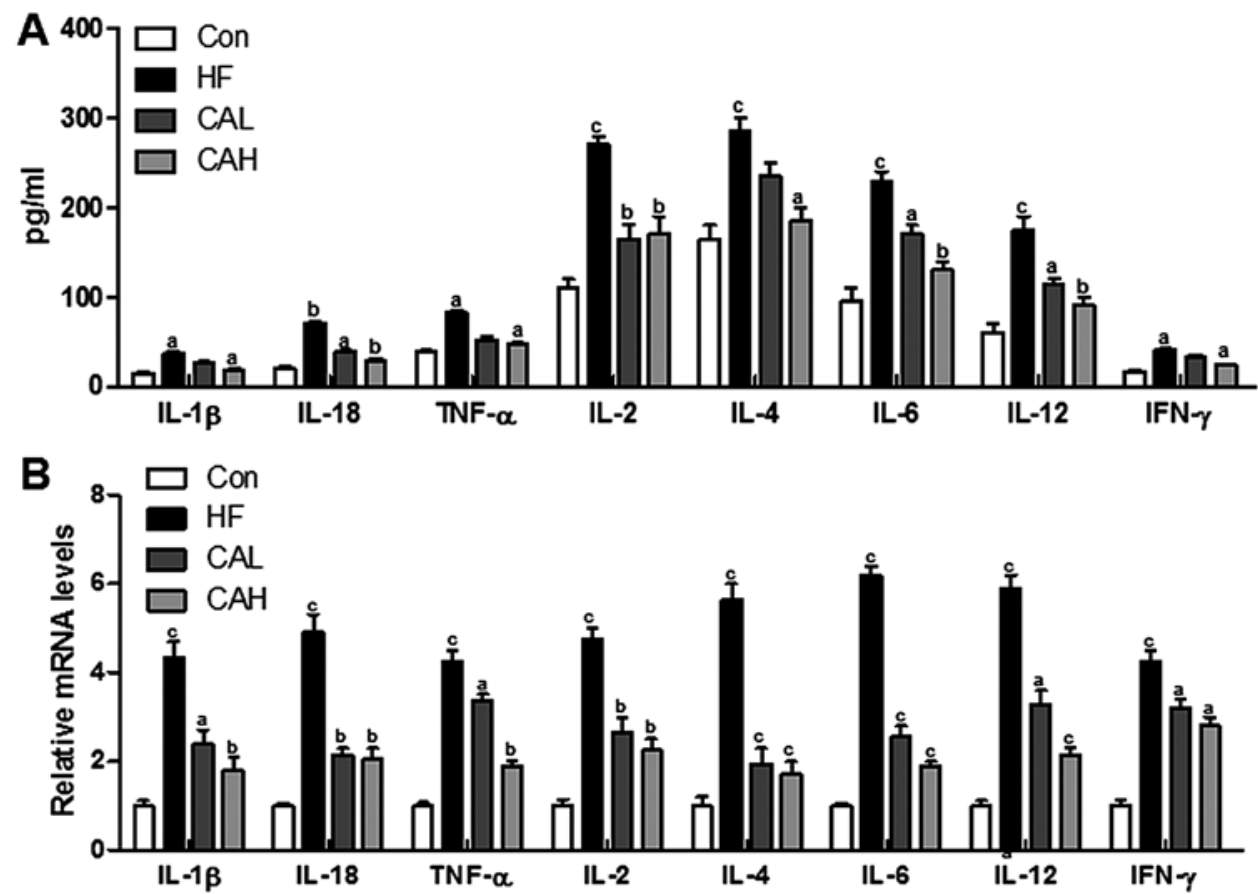

Figure 9. Carnosic acid reduces pro-inflammatory cytokine expression in mice fed a high-fat (HF) diet. (A) Serum interleukin (IL)-1 $\beta$, IL-18, tumor necrosis factor- $\alpha$ (TNF- $\alpha$ ), IL-2, IL-4, IL-6, IL-12 and interferon- $\gamma$ (IFN- $\gamma$ ) levels were determined by ELISA. (B) mRNA levels in liver tissue samples were calculated by RT-qPCR. Results are the means \pm SD of 8 mice/group. HF vs. the Con group; CAL and CAH vs. the HF group. ${ }^{a} p<0.05,{ }^{b} p<0.01$ and ${ }^{c} p<0.001$. 
A
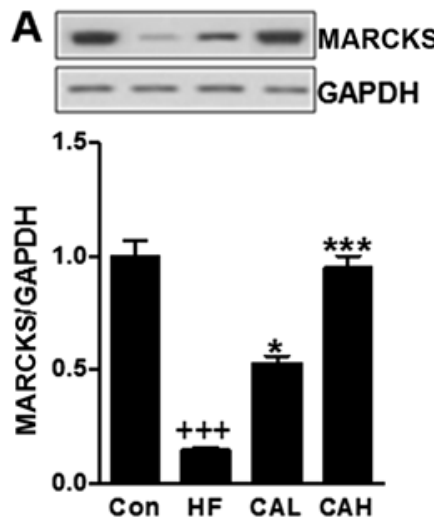
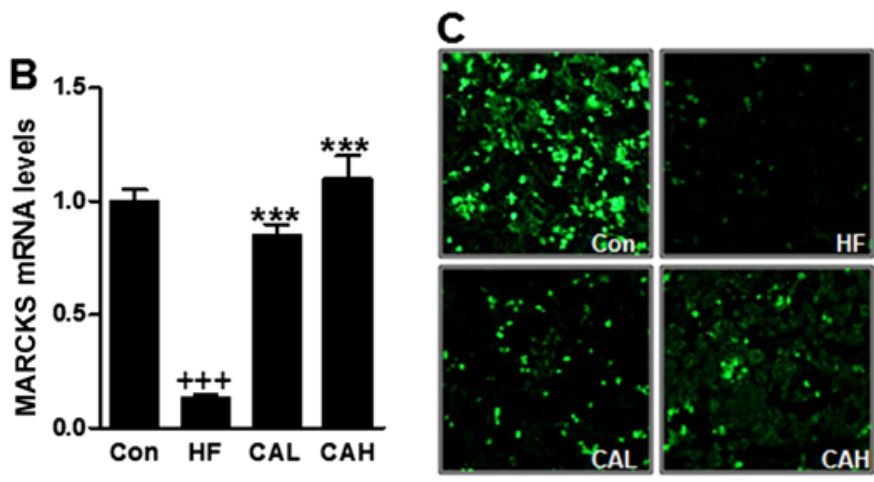

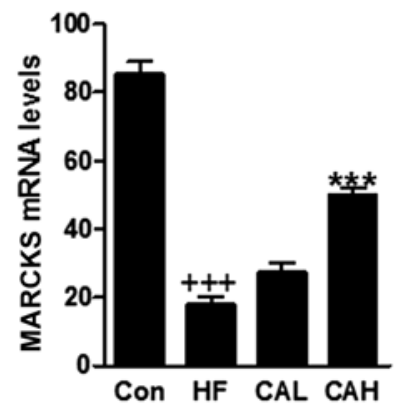

Figure 10. Carnosic acid increases myristoylated alanine-rich C-kinase substrate (MARCKS) expression in mice fed a high-fat (HF) diet. (A) Representative western blots of MARCKS. (B) RT-qPCR analysis of MARCKS. (C) Immunofluorescence analysis of MARCKS. Results are the means \pm SD of 8 mice/group. ${ }^{+++} \mathrm{p}<0.001$ vs. the Con group; ${ }^{*} \mathrm{p}<0.05$ and ${ }^{* * * *} \mathrm{p}<0.001$ vs. the HF group.

cells was observed in the control group; however, only a few MARCKS-positive cells were observed in the HF diet-fed mice, which were stimulated in mice with HF diet (Fig. 10C). These data indicated that CA attenuates NAFLD in mice fed a HF diet by regulating MARCKS expression.

$C A$ protects mice against $H F$ diet-induced liver injury by suppressing PI3K/AKT and NLRP3 inflammasome signaling pathway activation.PI3K/AKT is a potential target of MARCKS in attenuating NAFLD based on the results mentioned above. A recent study demonstrated that $\mathrm{CA}$ treatment attenuated the inflammatory response by regulating the $\mathrm{NF}-\kappa \mathrm{B}$ signaling pathway (40). To confirm this conclusion, we measured the levels of PI3K/AKT in the livers of mice fed a HF diet and treated with $\mathrm{CA}$. We found that the upregulation of PI3K and p-AKT were reduced by carnosic acid in liver of mice with HF diet induction (Fig. 11A). Increased PI3K/AKT was also a pivotal factor for inducing $N F-\kappa B$ activation (41). Therefore, we examined whether NLRP3 and NF- $\kappa \mathrm{B}$ expression in the liver was altered by CA. The overexpression of NLRP3 and the phophorylated levels of $\mathrm{NF}-\kappa \mathrm{B}$ in the $\mathrm{HF}$ diet-fed mice were reduced by $\mathrm{CA}$ treatment, whereas the levels of total NF- $\mathrm{B}$ were not affected by CA (Fig. 11B). Caspase-1 was stimulated in HF diet fed mice, which was down-regulated due to carnosic acid administration, leading to $\mathrm{NF}-\kappa \mathrm{B}$ inactivity and pro-inflammatory cytokines suppression, including IL-1 $\beta$ and IL-18 (Fig. 11C). These data indicated that PI3K/AKT and NLRP3/NF- $\mathrm{B}$ in the liver may be involved in the inhibitory effects of CA against the inflammatory response in mice with NAFLD induced by a HF diet.

CA inhibits lipogenesis-related signaling pathway activation. In the end of the treatment period, we investigated whether lipogenesis is affected by CA. To examine this, we measured the expression levels of several key transcriptional factors in lipogenesis, including SREBP-1c, ACC $\alpha$, FAS and SCD1. The overexpression of SREBP-1c, ACC $\alpha$, FAS and SCD1, induced by the HF diet, was significantly attenuated by CA (Fig. 12A). Moreover, we also examined the PPAR $\alpha$ levels by immunohistochemical assays, and the results revealed that PPAR $\alpha$ expression was downregulated in the HF diet-fed mice, and that this effect was reversed by CA (Fig. 12B). The mRNA level of PPAR $\alpha$ was also decreased in the mice fed the HF diet, and similar to the data mentioned above, CA increased PPAR $\alpha$ mRNA expression (Fig. 12C). These results clearly indicated that CA treatment suppressed lipogenesis in HF diet induced animals with NAFLD.

\section{Discussion}

NAFLD is the hepatic manifestation of obesity and insulin resistance $(1,2,42)$. The progression involves the development of liver steatosis, increased inflammation and hepatocyte injury, and eventually the deposition of extracellular matrix proteins, leading to liver fibrosis and cirrhosis. The clinical features of NAFLD include obesity, insulin resistance and dyslipidemia. The consumption of a HF diet is an important factor in the increasing occurrence of these metabolic disorders, primarily NAFLD (43). MARCKS is an intrinsically unfolded protein with a conserved cationic effector domain, regulating the crosstalk between several signaling transduction pathways. MARCKS has been shown to be involved in the regulation of cell adhesion and migration, of exocytosis, endocytosisand phagocytosis, as well as brain development $(44,45)$. MARCKS has been investigated in cancer progression and LPS-induced disease from PI3K/AKT and inflammation-related signaling pathways (46). However, the effects of MARCKS on NAFLD development have not been fully determined. Thus, in this present study, we attempted to examine the role of MARCKS in HF diet-induced NAFLD in mice and to elucidate the underlying mechanisms. In addition, we examined the effects of CA, which is an essential antioxidant compound in Rosmarinus officinalis L., on liver cancer. CA has anticancer effects on colon cancer, acute myeloid leukemia and skin cancer through anti-inflammatory, antioxidant and antimicrobial properties. However, the molecular mechanisms responsible for NAFLD remain poorly understood. In the present study, the consumption of a HF diet decreased the expression of MARCKS in mouse livers, suggesting a role of MARCKS in modulating the pathogenesis of NAFLD. However, the genetic deletion of MARCKS increased hepatic steatosis, the inflammatory response, lipid accumulation and ALT/AST levels in the liver in response to a HF diet. Taken together, these data suggest that the inhibition of MARCKS exacerbates the fibrotic response to a HF diet. 
A Con HF CAL CAH
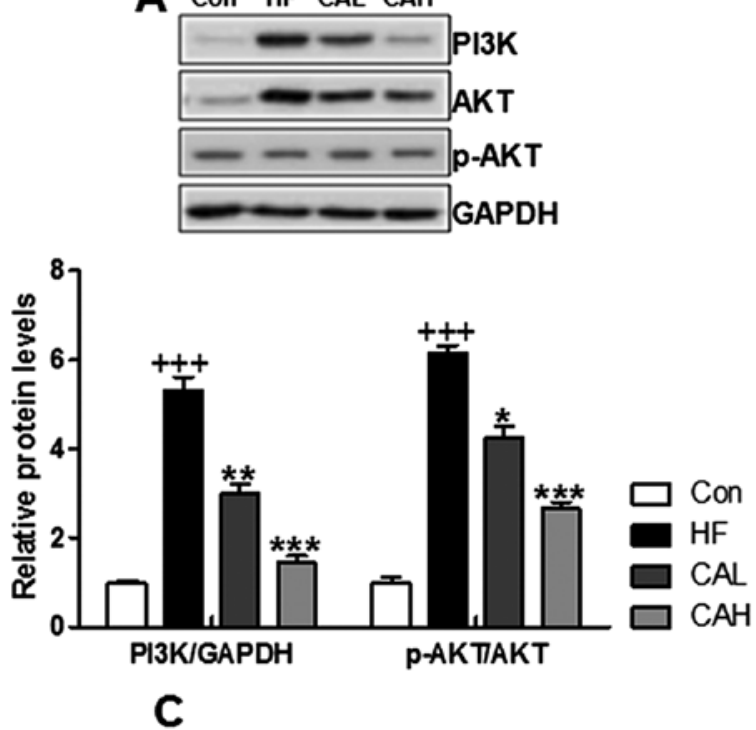

Con HF CAL CAH

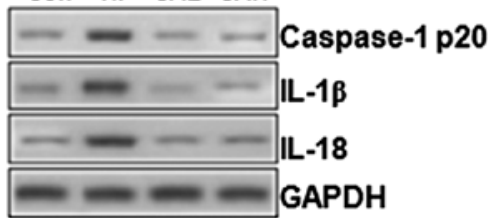

B
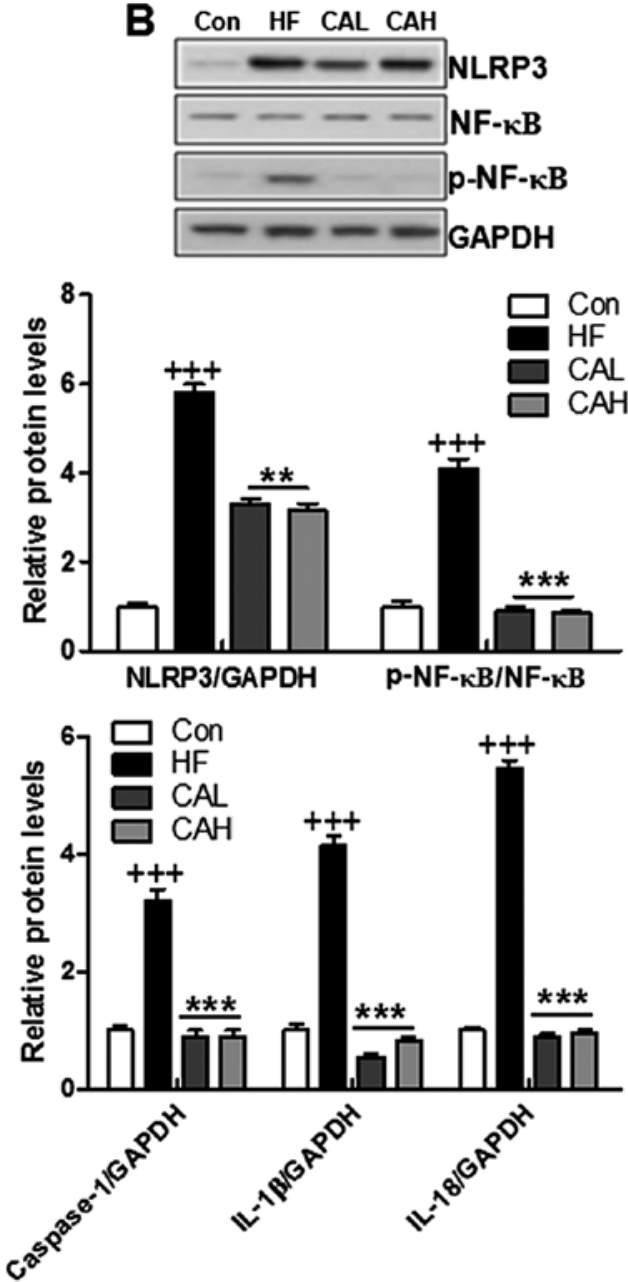

Figure 11. Carnosic acid protects against high-fat (HF) diet-induced liver injury by suppressing PI3K/AKT and NLRP3 inflammasome signaling.

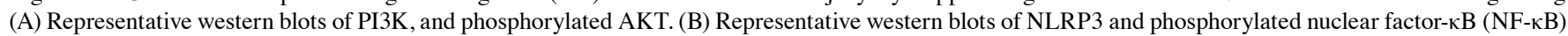
(C) Representative western blots of caspase-1, interleukin (IL)-1 $\beta$ and IL-18. Results are the means \pm SD of 8 mice/group. ${ }^{++}$p $<0.001$ vs. the Con group; ${ }^{*} p<0.05$, ${ }^{* *} \mathrm{p}<0.01$ and ${ }^{* * *} \mathrm{p}<0.001$ vs. the HF group.

First of all, we used MARCKS-deficient mice to construct a model of HF diet-induced NAFLD model in order to investigate the effects of MARCKS in NAFLD. Insulin resistance or impaired insulin signaling is a main contributor to the disruption of glucose metabolism and plays a pivotal role in pathogenesis of T2DM $(47,48)$. Reciprocally, the improvement or restoration of insulin signaling is an effective treatment for restoring abnormal glucose metabolism in T2DM (49). In this study, we found that MARCKS deficiency increased glucose levels in serum and accelerated insulin resistance in HF diet-fed mice. Thus, we hypothesized that MARCKS may play a potential role in regulating insulin resistance in mice with NAFLD induced by a HF diet. Of note, CA administration not only improved MARCKS expressed levels from mRNA and protein levels, but also improved insulin sensitivity from down-regulating glucose levels in blood. In the insulin signal pathway, Akt is a central regulator for insulin signal transduction and accumulating evidences revealed that many chemicals activating Akt signal have potential role in improving insulin signal transduction $(50,51)$. Previous data have revealed that MARCKS has a close association with AKT activity in cancer (30). In this study, $\mathrm{PI} 3 \mathrm{~K} / \mathrm{AKT}$ signaling pathway activity was increased in mice deficient in MARCKS, suggesting that MARCKS plays a role in suppressing AKT activity in HF diet-fed mice with NAFLD. Thus, the administration of CA improved glucose homeostasis in the HF diet-fed mice with NAFLD. Also, carnosic acid showed inhibitory role in mediating AKT activity, which might be related to the suppressive effects of MARCKS on AKT activity.

The reasons for ameliorated insulin signal transduction in liver tissues are probably due to the downregulation of circulating pro-inflammatory cytokines (52). The inflammatory response in the livers of mice with NAFLD is widely considered as a key factor for inducing systemic insulin resistance (53). Pro-inflammatory cytokines, including TNF $\alpha$, IL-18, IL-2, IL-4, IL-1 $\beta$ and IL-6, disrupt the insulin sensitivity of adipocytes and liver (54). In this study, demonstrated that the expression levels of pro-inflammatory cytokines in serum and liver tissues were greatly increased in MARCKS-deficient mice the HF diet. In the HF diet-fed mice, the levels of these pro-inflammatory cytokines were suppressed by CA. In agreement with our results, it has been shown that CA inhibits the inflammation through reducing the release of pro-inflammatory cytokines (55). NF-kB signaling-related factors are involved in inflammatory responses (56). The key components of the functional NLRP3 inflammasome include NLRP3 and caspase-1. The activation of the NLRP3 inflammasome increases the 
A

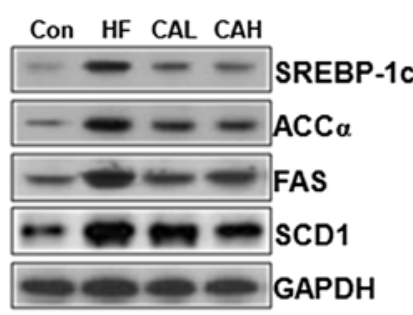

B

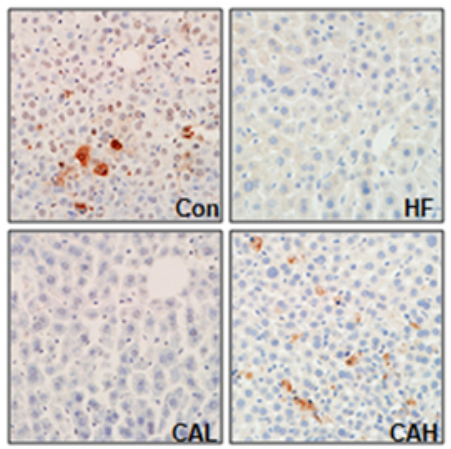

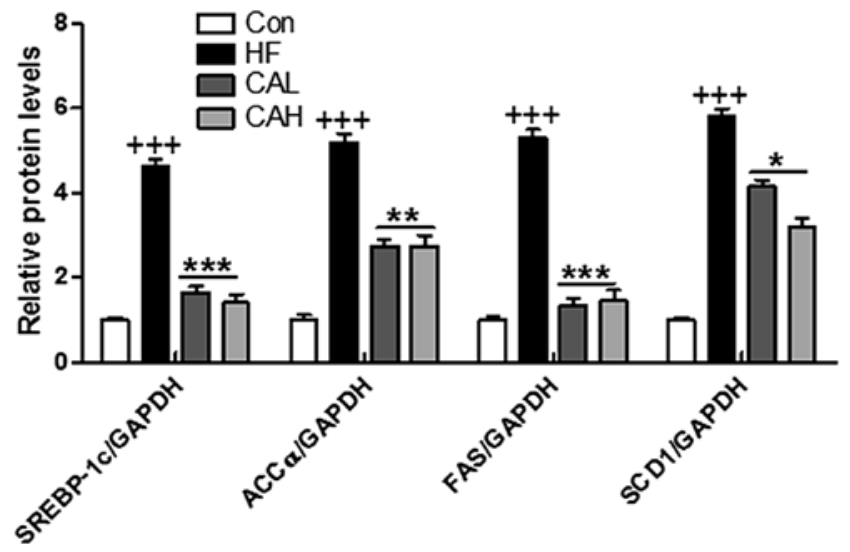
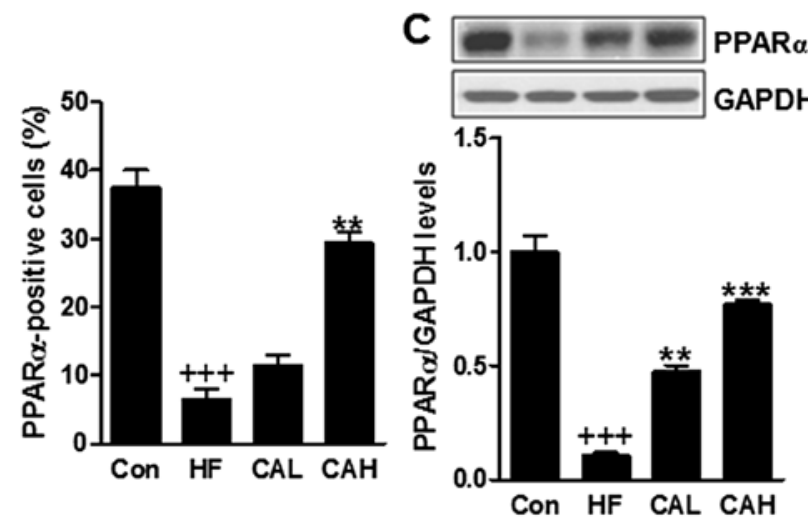

Figure 12. Carnosic acid inhibits lipogenesis-related signaling pathway activation. (A) Representative western blots of SREBP-1c, ACC $\alpha$, FAS and SCD1. (B) Immunohistochemical analysis of peroxisome proliferator-activated receptor $\alpha$ (PPAR $\alpha$ ) in the liver tissue samples of mice fed a high-fat (HF) diet. (C) Representative western blot of PPAR $\alpha$ protein levels. Results are the means \pm SD of 8 mice/group. ${ }^{+++}$p $<0.001$ vs. the Con group; ${ }^{*}$ p $<0.05$, ${ }^{* *}$ p $<0.01$ and **** $\mathrm{p}<0.001$ vs. the HF group.

maturation and release of pro-inflammatory cytokines, such as IL-1 $\beta$ and pro-IL-18 potently (57). In this study, we found that MARCKS deficiency stimulated NLRP3 expression, leading to caspase-1 activation and causing pro-inflammatory cytokine release through $\mathrm{NF}-\kappa \mathrm{B}$ phosphorylation. Here, the secretion of pro-inflammatory cytokines in liver of mice with HF diet are greatly suppressed by CA.

In addition to inflammation, lipid accumulation was also affected by MARCKS and CA. Our results revealed a marked enhancement of TG and TC accumulation in the MARCKSdeficient mice fed the HF diet. MARCKS deficiency led to lipid accumulation in HF diet fed mice, indicating that MARCKS, at least partly, could influence lipid metabolism in mice with NAFLD. In addition, a marked reduction in the levels of TGs and TC in mice treated with CA was observed in our study, suggesting that $\mathrm{CA}$ has a lipid-regulating effect. SREBP-1c is a member of the family of SREBP membrane-bound transcription factors, activating the transcription of lipogenic genes, which contain the sterol regulatory elements in their promoter regions, including FAS and SCD1. The expression of two genes in particular, FAS and SCD1, is closely related to the levels of the de novo fatty acid synthesis and to cellular lipid accumulation ultimately (58). Some lines of evidence have indicated that the induction of SREBP-1c expression in the liver aids in the enhancement of hepatic TG concentrations, causing the progression of NAFLD (59). Consistently, in our study, SREBP-1c, FAS and SCD1 were upregulated in mice fed a HF diet, and this effect was enhanced in the MARCKS-deficient mice, leading to a high expression of FAS and SCD1, indicating that MARCKS is involved in lipid metabolism in mice with NAFLD. However, the specific underlying mechanisms require further investigation. PPAR $\alpha$ is a major transcriptional regulator of lipid metabolism, which is involved in fatty acid $\beta$-oxidation (60). This study demonstrated that PPAR $\alpha$ expression was downregulated by MARCKS deficiency in HF diet-fed mice. By contrast, PPAR $\alpha$ was upregulated due to CA administration in mice with fed the HF diet. The present study showed that carnosic acid reduced lipogenesis in HF diet-induced mice with NAFLD, which might be linked to MARCKS upregulation.

In conclusion, the findings of the present study reveal a protective effect of MARCKS of MARCKS on mice treated with a HF diet. Our data indicate that MARCKS may protect the liver from the lipid accumulation, inflammation, fibrosis in the context of NAFLD and the damaged glucose homeostasis. In addition, our results revealed that CA possesses the ability to improve high fat diet-induced NAFLD in mice through reducing the lipogenesis and inflammation in liver. Therefore, our data indicate that CA may be used as a potential therapeutic agent in the treatment of NAFLD-related metabolic diseases, including insulin resistance and lipid abnormal metabolism.

\section{Acknowledgements}

Not applicable 


\section{Funding}

No funding was received.

\section{Availability of data and materials}

All data generated or analyzed during this study are included in this published article.

\section{Authors' contributions}

HMZ conceived the study. HMS and XL designed and performed most of the experiments and wrote the mamusript. YYL and LZ assisted with some of the animal experiments. DY analyzed the data. WPL and ZHC provided tissue samples and advice on histological experiments. All autors read and discussed the manuscript. All authors approved the final manuscript.

\section{Ethics approval and consent to participate}

This study was approved by the Ethics Committee on Animal Research at the Department of Otolaryngology-Head and Neck Surgery, Huai'an Hospital Affiliated to Xuzhou Medical College, Huaian, China.

\section{Consent for publication}

Not applicable

\section{Competing interests}

The authors declare that they have no competing interests.

\section{References}

1. Duvnjak M, Lerotić I, Barsić N, Tomasić V, Virović Jukić L and Velagić V: Pathogenesis and management issues for non-alcoholic fatty liver disease. World J Gastroenterol 13: 4539-4550, 2007.

2. Angulo P: Nonalcoholic fatty liver disease. N Engl J Med 346: 1221-1231, 2002.

3. Postic C and Girard J: The role of the lipogenic pathway in the development of hepatic steatosis. Diabetes Metab 34: 643-648, 2008.

4. Yeh MM and Brunt EM: Pathology of nonalcoholic fatty liver disease. Am J Clin Pathol 128: 837-847, 2007.

5. Estep JM, Baranova A, Hossain N, Elariny H, Ankrah K, Afendy A, Chandhoke V and Younossi ZM: Expression of cytokine signaling genes in morbidly obese patients with nonalcoholic steatohepatitis and hepatic fibrosis. Obes Surg 19 617-624, 2009.

6. Lam B and Younossi ZM: Treatment options for nonalcoholic fatty liver disease. Therap Adv Gastroenterol 3: 121-137, 2010.

7. Huang MT, Ho CT, Wang ZY, Ferraro T, Lou YR, Stauber K, Ma W, Georgiadis C, Laskin JD and Conney AH: Inhibition of skin tumorigenesis by rosemary and its constituents carnosol and ursolic acid. Cancer Res 54: 701-708, 1994.

8. Shi B, Wang LF, Meng WS, Chen L and Meng ZL: Carnosic acid and fisetin combination therapy enhances inhibition of lung cancer through apoptosis induction. Int J Oncol 50: 2123-2135, 2017.

9. Moran AE, Carothers AM, Weyant MJ, Redston M and Bertagnolli MM: Carnosol inhibits beta-catenin tyrosine phosphorylation and prevents adenoma formation in the C57BL/6J/ Min/ + (Min/+) mouse. Cancer Res 65: 1097-1104, 2005.

10. Sharabani H, Izumchenko E, Wang Q, Kreinin R, Steiner M, Barvish Z, et al: Cooperative antitumor effects of vitamin D3 derivatives and rosemary preparations in a mouse model of myeloid leukemia. Int J Cancer 118: 3012-3021, 2006.
11. Jarboe JS, Anderson JC, Duarte CW, Mehta T, Nowsheen S, Hicks PH, Whitley AC, Rohrbach TD, McCubrey RO, Chiu S, et al: MARCKS regulates growth and radiation sensitivity and is a novel prognostic factor for glioma. Clin Cancer Res 18: 3030$3041,2012$.

12. Brooks G, Brooks SF and Goss MW: MARCKS functions as a novel growth suppressor in cells of melanocyte origin. Carcinogenesis 17: 683-689, 1996.

13. BickeböllerM,TagschererKE,Kloor M,Jansen L,Chang-Claude J, Brenner H, Hoffmeister M, Toth C, Schirmacher P, Roth W, et al: Functional characterization of the tumor-suppressor MARCKS in colorectal cancer and its association with survival. Oncogene 34: 1150-1159, 2015.

14. Kim J, Shishido T, Jiang X, Aderem A and McLaughlin S: Phosphorylation, high ionic strength, and calmodulin reverse the binding of MARCKS to phospholipid vesicles. J Bio Chem 269: 28214-28219, 1994.

15. Lippoldt J, Händel C, Dietrich U and Käs JA: Dynamic membrane structure induces temporal pattern formation. BBA-Biomembranes 1838: 2380-2390, 2014.

16. Rombouts K, Lottini B, Caligiuri A, Liotta A, Mello T, Carloni V, Marra F and Pinzani M: MARCKS is a downstream effector in platelet-derived growth factor-induced cell motility in activated human hepatic stellate cells. Exp Cell Res 314: 1444-1454, 2008.

17. Yu D, Makkar G, Strickland DK, Blanpied TA, Stumpo DJ, Blackshear PJ, Sarkar R and Monahan TS: Myristoylated alanine-rich protein kinase substrate (MARCKS) regulates small GTPase Rac1 and Cdc42 activity and is a critical mediator of vascular smooth muscle cell migration in intimal hyperplasia formation. J Am Heart Assoc 4: e002255, 2015.

18. Zhao Y and Davis HW: Thrombin-induced phosphorylation of the myristoylated alanine-rich $C$ kinase substrate (MARCKS) protein in bovine pulmonary artery endothelial cells. J Cell Physiol 169: 350-357, 1996.

19. Campbell JS, Hughes SD, Gilbertson DG, Palmer TE, Holdren MS, Haran AC, Odell MM, Bauer RL, Ren HP, Haugen HS, et al: Platelet-derived growth factor C induces liver fibrosis, steatosis, and hepatocellular carcinoma. Proc Natl Acad Sci USA 102: 3389-3394, 2005.

20. Diehl AM, Li ZP, Lin HZ and Yang SQ: Cytokines and the pathogenesis of non-alcoholic steatohepatitis. Gut 54: 303-306, 2005.

21. Abiru S, Migita K, Maeda Y, Daikoku M, Ito M, Ohata K, Nagaoka S, Matsumoto T, Takii Y, Kusumoto K, et al: Serum cytokine and soluble cytokine receptor levels in patients with non-alcoholic steatohepatitis. Liver Int 26: 39-45, 2006.

22. Neuschwander-Tetri BA, Brunt EM, Wehmeier KR, Oliver D and Bacon BR: Improved nonalcoholic steatohepatitis after 48 weeks of treatment with the PPAR- $\gamma$ ligand rosiglitazone. Hepatology 38: 1008-1017, 2003

23. Ratziu V, Harrison SA, Francque SM, Bedossa P, Serfaty L, Gomez MR, et al: An international, phase 2 randomized controlled trial of the dual PPAR $\alpha-\delta$ agonist GFT505 in adult patients with NASH. Hepatology 62: 262A-263A, 2015.

24. Abitbol JL, Broqua P and Junien JL: Metabolic effects and good tolerance of IVA337 a Pan-PPAR agonist in diabetic patients warrant further investigation in NASH. J Hepatol 64: S189, 2016.

25. Pettinelli P, Del Pozo T, Araya J, Rodrigo R, Araya AV, Smok G, Csendes A, Gutierrez L, Rojas J, Korn O, et al: Enhancement in liver SREBP-1c/PPAR- $\alpha$ ratio and steatosis in obese patients: correlations with insulin resistance and n-3 long-chain polyunsaturated fatty acid depletion. Biochim Biophys Acta 1792: 1080-1086, 2009.

26. Bajaj M, Suraamornkul S, Hardies LJ, Glass L, Musi N and DeFronzo RA: Effects of peroxisome proliferator-activated receptor (PPAR)- $\alpha$ and PPAR- $\gamma$ agonists on glucose and lipid metabolism in patients with type 2 diabetes mellitus. Diabetologia 50: 1723-1731, 2007

27. Acikgoz Y, Can B, Bek K, Acikgoz A, Ozkaya O, Genç G and Sarikaya S: The effect of simvastatin and erythropoietin on renal fibrosis in rats with unilateral ureteral obstruction. Ren Fail 36: 252-257, 2014.

28. Mohamed JS, Lopez MA and Boriek AM: Mechanical stretch upregulates microRNA-26a and induces human airway smooth muscle hypertrophy by suppressing glycogen synthase kinase- $3 \beta$. J Biol Chem 285: 29336-29347, 2010.

29. Baker RG, Hayden MS and Ghosh S: NF- $\mathrm{B}$, inflammation, and metabolic disease. Cell Metab 13: 11-22, 2011.

30. Chen CH, Statt S, Chiu CL, Thai P, Arif M, Adler KB and Wu R: Targeting myristoylated alanine-rich $C$ kinase substrate phosphorylation site domain in lung cancer. Mechanisms and therapeutic implications. Am J Resp Crit Care 190: 1127-1138, 2014. 
31. Dos Santos S, Delattre AI, De Longueville F, Bult H and Raes M: Gene expression profiling of LPS-stimulated murine macrophages and role of the $\mathrm{NF}-\mathrm{\kappa B}$ and $\mathrm{PI} 3 \mathrm{~K} / \mathrm{mTOR}$ signaling pathways. Ann NY Acad Sci 1096: 70-77, 2007.

32. Hayden MS and Ghosh S: Shared principles in NF-kappaB signaling. Cell 132: 344-362, 2008.

33. Tatsumi S, Mabuchi T, Katano T, Matsumura S, Abe T, Hidaka H, Suzuki M, Sasaki Y, Minami T and Ito S: Involvement of Rho-kinase in inflammatory and neuropathic pain through phosphorylation of myristoylated alanine-rich C-kinase substrate (MARCKS). Neuroscience 131: 491-498, 2005.

34. Raghow R, Yellaturu C, Deng X, Park EA and Elam MB: SREBPs: the crossroads of physiological and pathological lipid homeostasis. Trends Endocrinol Metab 19: 65-73, 2008.

35. Blankenship K, Gilley A, Piekarski A, Orlowski S, Greene E, Bottje W, Anthony N and Dridi S: Differential expression of feeding-related hypothalamic neuropeptides in the first generation of quails divergently selected for low or high feed efficiency. Neuropeptides 58: 31-40, 2016

36. Chen H, Zhang L, Li X, Li X, Sun G, Yuan X, Lei L, Liu J, Yin L, Deng Q, et al: Adiponectin activates the AMPK signaling pathway to regulate lipid metabolism in bovine hepatocytes. J Steroid Biochem 138: 445-454, 2013.

37. Dossi CG, Tapia GS, Espinosa A, Videla LA and D'Espessailles A Reversal of high-fat diet-induced hepatic steatosis by $n-3$ LCPUFA: role of PPAR- $\alpha$ and SREBP-1c. J Nutr Biochem 25 977-984, 2014

38. Pawlak M, Lefebvre P and Staels B: Molecular mechanism of PPAR $\alpha$ action and its impact on lipid metabolism, inflammation and fibrosis in non-alcoholic fatty liver disease. J Hepatol 62 : 720-733, 2015

39. du Plessis J, Korf H, van Pelt J, Windmolders P, Vander Elst I, Verrijken A, Hubens G, Van Gaal L, Cassiman D, Nevens F et al: Pro-inflammatory cytokines but not endotoxin-related parameters associate with disease severity in patients with NAFLD. PloS One 11: e0166048, 2016.

40. Lin CY, Chen JH, Fu RH and Tsai CW: Induction of Pi form of glutathione $\mathrm{S}$-transferase by carnosic acid is mediated through $\mathrm{PI} 3 \mathrm{~K} / \mathrm{Akt} / \mathrm{NF}-\kappa \mathrm{B}$ pathway and protects against neurotoxicity. Chem Res Ttoxicol 27: 1958-1966, 2014.

41. Zhao M, Zhou A, Xu L and Zhang X: The role of TLR4-mediated $\mathrm{PTEN} / \mathrm{PI} 3 \mathrm{~K} / \mathrm{AKT} / \mathrm{NF}-\kappa \mathrm{B}$ signaling pathway in neuroinflammation in hippocampal neurons. Neuroscience 269: 93-101, 2014

42. Boppidi H and Daram SR: Nonalcoholic fatty liver disease: hepatic manifestation of obesity and the metabolic syndrome. Postgrad Med 120: E01-E07, 2008.

43. Nakamura A and Terauchi Y: Lessons from mouse models of high-fat diet-induced NAFLD. Int J Mol Sci 14: 21240-21257, 2013.

44. Orecchia A, Mettouchi A, Uva P, Simon GC, Arcelli D, Avitabile S, Ragone G, Meneguzzi G, Pfenninger KH, Zambruno G and Failla CM: Endothelial cell adhesion to soluble vascular endothelial growth factor receptor-1 triggers a cell dynamic and angiogenic phenotype. FASEB J 28: 692-704, 2014

45. Dorris E, O'Neill A, Hanrahan K, Treacy A and Watson RW: MARCKS promotes invasion and is associated with biochemical recurrence in prostate cancer. Oncotarget 8: 72021, 2017.

46. Lee SM, Suk K and Lee WH: Myristoylated alanine-rich C kinase substrate (MARCKS) regulates the expression of proinflammatory cytokines in macrophages through activation of $\mathrm{p} 38$ JNK MAPK and NF-кB. Cell Immunol 296: 115-121, 2015.
47. Zheng S, Hoos L, Cook J, Tetzloff G, Davis H Jr, van Heek M and Hwa JJ: Ezetimibe improves high fat and cholesterol diet-induced non-alcoholic fatty liver disease in mice. Eur J Pharmacol 584: $118-124,2008$

48. Matono T, Koda M, Tokunaga S, Kato J, Sugihara T, Ueki M and Murawaki Y: Therapeutic effects of ezetimibe for non-alcoholic steatohepatitis in fatty liver shionogi-ob/ob mice. Hepatol Res 41: 1240-1248, 2011.

49. Kishino Y, Tanaka Y, Ikeda T, Yamamoto K, Ogawa H, Iwatani Y and Kamisako T: Ezetimibe increases hepatic iron levels in mice fed a high-fat diet. J Pharmacol Exp Ther 345: 483-491, 2013.

50. Choi K and Kim YB: Molecular mechanism of insulin resistance in obesity and type 2 diabetes. Korean J Intern Med 25: 119-129, 2010.

51. Mackenzie RW and Elliott BT: Akt/PKB activation and insulin signaling: A novel insulin signaling pathway in the treatment of type 2 diabetes. Diabetes Metab Syndr Obes 7: 55-64, 2014.

52. Bagul PK, Middela H, Matapally S, Padiya R, Bastia T, Madhusudana K, Reddy BR, Chakravarty S and Banerjee SK: Attenuation of insulin resistance, metabolic syndrome and hepatic oxidative stress by resveratrol in fructose-fed rats. Pharmacol Res 66: 260-268, 2012.

53. Chandrashekaran V, Dattaroy D, Das S, Alhasson F, Seth R, Carson J, Berger F, Zielnoka J, Kalyanaraman B and Chatterjee S: The receptor for advanced glycation end product (RAGE) binding to HMGB1 and subsequent NADPH oxidase activation mediates ectopic intestinal inflammation in NAFLD. Free Radical Biol Med 100: S37, 2016.

54. Calle MC and Fernandez ML: Inflammation and type 2 diabetes. Diabetes Metab 38: 183-191, 2012.

55. Hadad $\mathrm{N}$ and Levy R: The synergistic anti-inflammatory effects of lycopene, lutein, $\beta$-carotene, and carnosic acid combinations via redox-based inhibition of $\mathrm{NF}-\kappa \mathrm{B}$ signaling. Free Radical Biol Med 53: 1381-1391, 2012.

56. Segovia J, Sabbah A, Mgbemena V, Tsai SY, Chang TH, Berton MT, Morris IR, Allen IC, Ting JP and Bose S: TLR2/ MyD88/NF- $x$ B pathway, reactive oxygen species, potassium efflux activates NLRP3/ASC inflammasome during respiratory syncytial virus infection. PLOs One 7: e29695, 2012.

57. Vandanmagsar B, Youm YH, Ravussin A, Galgani JE, Stadler K, Mynatt RL, Ravussin E, Stephens JM and Dixit VD: The NLRP3 inflammasome instigates obesity-induced inflammation and insulin resistance. Nat Med 17: 179-188, 2011.

58. Fu S, Yang L, Li P, Hofmann O, Dicker L, Hide W, Lin X, Watkins SM, Ivanov AR and Hotamisligil GS: Aberrant lipid metabolism disrupts calcium homeostasis causing liver endoplasmic reticulum stress in obesity. Nature 473: 528-531, 2011.

59. Ahmed MH and Byrne CD: Modulation of sterol regulatory element binding proteins (SREBPs) as potential treatments for non-alcoholic fatty liver disease (NAFLD). Drug Discov Today 12: 740-747, 2007.

60. Reddy JK: Peroxisomal $\beta$-oxidation, PPAR $\alpha$, and steatohepatitis. Am J Physiol-Gastr L 281: G1333-G1339, 2001

This work is licensed under a Creative Commons Attribution-NonCommercial-NoDerivatives 4.0 International (CC BY-NC-ND 4.0) License. 